\title{
Acquisition and expression of conditioned taste aversion differentially affects extracellular signal regulated kinase and glutamate receptor phosphorylation in rat prefrontal cortex and nucleus accumbens
}

\author{
Roberto Marotta ${ }^{1 \neq}$, Sandro Fenu ${ }^{2,3,4+7}$, Simona Scheggi ${ }^{5 t}$, Stefania Vinci ${ }^{2}$, Michela Rosas ${ }^{6 \dagger}$, \\ Andrea Falqui ${ }^{1}$, Carla Gambarana ${ }^{5 t}$, M. Graziella De Montis ${ }^{5 t}$ and Elio Acquas M $^{2,3,4 * t}$ \\ EM Laboratory, Department of Nanochemistry, Istituto Italiano di Tecnologia - IIT, Genova, Italy \\ ${ }^{2}$ Department of Toxicology, University of Cagliari, Cagliari, Italy \\ ${ }^{3}$ Centre of Excellence on Neurobiology of Addiction, University of Cagliari, Cagliari, Italy \\ ${ }^{4}$ National Institute of Neuroscience - INN, University of Cagliari, Cagliari, Italy \\ ${ }^{5}$ Department of Neuroscience, University of Siena, Siena, Italy \\ ${ }^{6}$ Department of Life and Environmental Sciences, University of Cagliari, Cagliari, Italy
}

\section{Edited by:}

Riccardo Brambilla, San Raffaele Scientific Institute and University, Italy

Reviewed by:

Gilberto Fisone, Karolinska Institutet, Sweden

Peter Vanhoutte, Centre National de la Recherche Scientifique, France

\section{*Correspondence:}

Elio Acquas, Department of Life and Environmental Sciences, University of Cagliari, Via Ospedale, 72,

1-09124 Cagliari, Italy

e-mail: acquas@unica.it

${ }^{\dagger}$ Present address:

Sandro Fenu, Department of

Biomedical Sciences, University of Cagliari, Cagliari, Italy;

Simona Scheggi, Carla Gambarana and M. Graziella De Montis,

Department of Molecular and

Developmental Medicine, University

of Siena, Siena, Italy;

Michela Rosas and Elio Acquas,

Pharmaceutical, Pharmacological

and Nutraceutical Sciences Section,

Department of Life and

Environmental Sciences, University

of Cagliari, Cagliari, Italy

¥ These authors have contributed

equally to this work.
Conditioned taste aversion (CTA) can be applied to study associative learning and its relevant underpinning molecular mechanisms in discrete brain regions. The present study examined, by immunohistochemistry and immunocytochemistry, the effects of acquisition and expression of lithium-induced CTA on activated Extracellular signal Regulated Kinase (p-ERK) in the prefrontal cortex (PFCx) and nucleus accumbens (Acb) of male Sprague-Dawley rats. The study also examined, by immunoblotting, whether acquisition and expression of lithium-induced CTA resulted in modified levels of phosphorylation of glutamate receptor subunits (NR1 and GluR1) and Thr ${ }^{34}$ - and $\mathrm{Thr}^{75}$-Dopamine-and-cAMP-Regulated PhosphoProtein (DARPP-32). CTA acquisition was associated with an increase of p-ERK-positive neurons and phosphorylated NR1 receptor subunit ( $p-N R 1$ ) in the PFCx, whereas $p$-GluR1, $p-T h r^{34}$ - and $p$-Thr ${ }^{75}$-DARPP-32 levels were not changed in this brain region. CTA expression increased the number of p-ERK-positive neurons in the shell (AcbSh) and core (AcbC) but left unmodified p-NR1, p-GluR1, p-Thr ${ }^{34}$ - and p-Thr ${ }^{75}$-DARPP-32 levels. Furthermore, post-embedding immunogold quantitative analysis in AcbSh revealed that CTA expression significantly increased nuclear p-ERK immunostaining as well as p-ERK-labeled axo-spinous contacts. Overall, these results indicate that ERK and NR1, but not GluR1 and DARPP-32, are differentially phosphorylated as a consequence of acquisition and expression of aversive associative learning. Moreover, these results confirm that CTA represents an useful approach to study the molecular basis of associative learning in rats and suggest the involvement of ERK cascade in learning-associated synaptic plasticity.

Keywords: conditioned taste aversion (CTA), extracellular signal regulated kinase (ERK), glutamate receptors, immuno electron microscopy, nucleus accumbens (Acb), prefrontal cortex (PFCx)

\section{INTRODUCTION}

Conditioned taste aversion (CTA) is a rapid to establish, robust, and long-lasting experimental model of associative learning based on animals' ability to avoid a taste (conditioned stimulus, CS) that has been previously associated with visceral malaise (unconditioned stimulus, US) (Garcia et al., 1955; Scott, 2011). In order to develop, CTA requires that a gustatory short-term memory trace is translated into the formation of long-term memory, i.e., gene expression (Berman et al., 1998) and into long-term molecular modifications (McGaugh, 2000) which can also be recapitulated as synaptic plasticity (Shiflett and Balleine, 2011). Accordingly,
CTA has offered, over the years, a valuable tool to investigate, in rodents, the neurotransmitter receptors (Fenu et al., 2001, 2005, 2009; Fenu and Di Chiara, 2003; Akirav, 2007; Barki-Harrington et al., 2009) involved in aversive associative learning, its underpinning molecular mechanisms (Berman et al., 1998; Yasoshima et al., 2006; Bernstein and Koh, 2007; Kwon and Houpt, 2012) as well as its anatomical substrates (Dunn and Everitt, 1988; Yamamoto et al., 1995; Berman et al., 1998; Ferreira et al., 2006; Ramírez-Lugo et al., 2007; Elkobi et al., 2008; Kwon and Houpt, 2012). In this regard, the analysis of neurochemical, molecular and neuroanatomical mechanisms involved in distinct phases 
(acquisition, consolidation, and expression) of CTA has long represented a significant approach to untangle their significance in aversive associative learning (Scott, 2011).

A large number of pharmacological studies, based on the use of receptor agonists and antagonists, supports the critical role that dopamine (DA) (Hoffman and Beninger, 1988; Fenu et al., 2001, 2005, 2009; Fenu and Di Chiara, 2003; Cannon et al., 2005) and glutamate (Yasoshima et al., 2000; Akirav, 2007; Simonyi et al., 2009; Núñez-Jaramillo et al., 2012), in particular, play in different brain regions and in distinct phases of CTA. Accordingly, DA and glutamate have been found to be concomitantly released in the insular cortex while memory consolidation is in progress and blockade of DA $\mathrm{D}_{1}$ and glutamate NMDA receptors, in this cortex, results in prevention of memory formation (Guzman-Ramos et al., 2010). Similarly, in agreement with the observation that $\mathrm{DA} \mathrm{D}_{1}$ receptor antagonists prevent aversive learning (Acquas et al., 1989; Acquas and Di Chiara, 1994; Fenu et al., 2001), blockade of DA $D_{1}$ receptors by systemic SCH 23390, as well as by local administration of SCH 39166 in the shell of the nucleus accumbens (AcbSh), impairs CTA learning (Fenu et al., 2001). Conversely, the $\mathrm{DA} \mathrm{D}_{1}$ and $\mathrm{D}_{2}$ receptor agonists, SKF38393 and quinpirole, respectively, have been shown to potentiate CTA acquisition (Hoffman and Beninger, 1988) and these effects are also mimicked by the indirect DA agonist d-amphetamine (Greenshaw and Buresová, 1982; Fenu and Di Chiara, 2003; Fenu et al., 2010). On the other hand, the role of glutamate transmission in the facilitation of the enduring changes underlying memory trace formation is supported by studies with NMDA receptor blockade (Rosenblum et al., 1997) and with NMDA receptor knock-out mice (Cui et al., 2005).

Among the molecular substrates worth of investigation in distinct phases of CTA, one of the most relevant and highly related to DA $D_{1}$ and glutamate NMDA receptor activation is Extracellular signal Regulated Kinase (ERK) (Girault et al., 2007; Shiflett and Balleine, 2011), a kinase deeply involved in mechanisms of signaling at the basis of synaptic plasticity (Fasano and Brambilla, 2011). In one of the first studies aimed to address the role of ERK activation during acquisition of an aversively conditioned response to a taste, it was demonstrated that its activation takes place after long- but not short-term taste memory in the insular cortex (Berman et al., 1998), a key area involved in processing of gustatory information (Dunn and Everitt, 1988). Furthermore, the ability of distinct phases of CTA to activate ERK phosphorylation has been investigated in a number of other brain regions including the amygdala (Languille et al., 2009; Lin et al., 2010), the hippocampus (Languille et al., 2009) and the prefrontal cortex (PFCx) (Mickley et al., 2005; Lin et al., 2010) and overall these data point to complex and differential brain region-, phase- and time-dependent patterns of ERK activation.

The PFCx and the Acb, because of their anatomical connections (Groenewegen et al., 1990), are viewed as brain areas relevant for associative memory formation, retention, and extinction under distinct aversive and fear learning tasks such as CTA (Fenu et al., 2001; Mickley et al., 2005; Ferreira et al., 2006; Yasoshima et al., 2006; Ramírez-Lugo et al., 2007; Lin et al., 2010) and trace fear conditioning (Runyan and Dash, 2004; Gilmartin and Helmstetter, 2010). In CTA experiments, in particular, the role of both PFCx (Mickley et al., 2005; Yasoshima et al., 2006; Lin et al., 2010) and Acb (Fenu et al., 2001; Fenu and Di Chiara, 2003; Núñez-Jaramillo et al., 2012) has been investigated but the involvement of ERK phosphorylation has only been addressed, to the best of our knowledge, in the PFCx during CTA extinction (Lin et al., 2010).

On the basis of these premises, the aim of the present study was to assess whether acquisition and expression of lithiuminduced CTA would result in a differential activation of ERK. This goal was accomplished by immunohistochemical experiments aimed at determining the changes of p-ERK-positive neurons counts in PFCx as well as in AcbSh and AcbC during CTA acquisition and expression. In addition, the analysis of PFCx and Acb molecular changes during these phases of CTA was extended to the assessment, by immunoblotting experiments, of the phosphorylation of glutamate receptor subunits (NR1 and GluR1) as well as of $\mathrm{Thr}^{34}$ - and $\mathrm{Thr}^{75}$-Dopamine-and-cAMPRegulated PhosphoProtein (DARPP-32). Finally, the study also aimed at assessing, by immuno electron microscopy, the subcellular (dendritic vs. somatic) distribution of ERK phosphorylation, as demonstrated in the immunohistochemical experiments, in the AcbSh of rats that expressed the acquired CTA.

\section{MATERIALS AND METHODS ANIMALS}

Male Sprague-Dawley rats (250-275 g) [Harlan Laboratories Srl, S. Pietro al Natisone (UD), Italy] were housed in groups of 4 per cage for at least 5 days before use and were maintained on a 12:00/12:00 h light/dark cycle (lights on at 8:00 a.m.) with food and water available ad libitum. Experiments were carried out between 10:00 a.m. and 2:00 p.m. All the experimental procedures were performed in accordance with the European and Italian legislation on the use and care of laboratory animals (EU Directive 2010/63 of September 22, 2010 and Italian D.L. 27.01 1992, n. 116). All efforts were made to minimize the number of animals used and their suffering.

\section{BEHAVIORAL EXPERIMENTS}

Behavioral experiments consisted of three phases [training, acquisition (conditioning) and expression (testing)] and lasted up to 8 days. In training, acquisition and expression phases the volumes of tap water and fresh sucrose solution drunk by rats were recorded.

\section{Training}

During this phase rats had to learn to consume their daily fluid intake in $20 \mathrm{~min} /$ day sessions. On the day before the beginning of training, rats were single-housed and the following day they were presented for $20 \mathrm{~min}$ with a graduated fluid reservoir filled with tap water after $24 \mathrm{~h}$ of water deprivation. Training took place along 6 days, i.e., until rats acquired a constant fluid intake, defined as at least three consecutive days in which fluid intake did not differ more than $10 \%$. During training rats' body weight was monitored and found to be not lower than $80 \%$ of that of other rats (same age) of the colony that did not undergo fluid restriction. 


\section{Acquisition (Acq)}

This phase followed the last day of training and lasted 1 day. During acquisition rats were presented a $15 \%(\mathrm{w} / \mathrm{v})$ sucrose solution or water as CS for $20 \mathrm{~min}$.

Experiment 1 (Acq1). One hour after drinking sucrose solution $\left(\mathrm{CS}^{+}\right)$or water $\left(\mathrm{CS}^{-}\right)$, rats were administered lithium chloride ( $\mathrm{LiCl}, 125 \mathrm{mg} / \mathrm{kg}$ i.p., in isotonic $-0.15 \mathrm{M}$ - solution) as unconditioned stimulus (US ${ }^{+}$) or saline i.p. (US ${ }^{-}$). Rats of these four groups (i.e., $\mathrm{CS}^{+}-\mathrm{US}^{+}$; $\mathrm{CS}^{-}-\mathrm{US}^{+}$; $\mathrm{CS}^{+}-\mathrm{US}^{-}$; $\mathrm{CS}^{-}-\mathrm{US}^{-}$) were anesthetized and underwent transcardiac perfusion for $\mathrm{p}$-ERK immunohistochemistry, $30 \mathrm{~min}$ after US presentation, in PFCx and Acb.

Experiment 2 (Acq2). In order to control for the effect of fluid deprivation and scheduled drinking, rats of two distinct groups, one presented with sucrose $\left(\mathrm{CS}^{+}\right)$, the other presented with water $\left(\mathrm{CS}^{-}\right)$, were anesthetized and underwent transcardiac perfusion for p-ERK immunohistochemistry, $30 \mathrm{~min}$ after $\mathrm{CS}^{+}$or $\mathrm{CS}^{-}$ presentation, in PFCx and Acb.

Experiment 3 (Acq3). In order to avoid a possible confounding factor in CTA acquisition response, due to the modifications induced by sucrose $\left(\mathrm{CS}^{+}\right)$consumption on NR1, GluR1, and DARPP-32 phosphorylation pattern (Danielli et al., 2010), rats were sacrificed $3 \mathrm{~h}$ after US. In particular, four separate groups of rats, two lithium-conditioned $\left(\mathrm{CS}^{+}-\mathrm{US}^{+}\right.$and $\left.\mathrm{CS}^{-}-\mathrm{US}^{+}\right)$and two control groups $\left(\mathrm{CS}^{+}\right.$-US $^{-}$and $\left.\mathrm{CS}^{-}{ }^{-} \mathrm{US}^{-}\right)$underwent a conditioning protocol with presentation of $\mathrm{CS}^{+}$or $\mathrm{CS}^{-}$and were sacrificed, $3 \mathrm{~h}$ after $\mathrm{US}^{+}$or $\mathrm{US}^{-}$, for immunoblotting detection of NR1, GluR1, Thr ${ }^{34}$ - and Thr ${ }^{75}$-DARPP-32 phosphorylation in PFCx and Acb.

\section{Expression (Expr)}

Expression tests took place $24 \mathrm{~h}$ after acquisition of CS-US association.

Experiment 4 (Expr1). In order to detect changes of p-ERK expression by immunohistochemistry in PFCx and Acb, two groups of rats, lithium-conditioned $\left(\mathrm{CS}^{+}-\mathrm{US}^{+}\right)$and controls $\left(\mathrm{CS}^{+}\right.$-US ${ }^{-}$), were presented the sucrose solution $\left(\mathrm{CS}^{+}\right)$for $20 \mathrm{~min}$ and $10 \mathrm{~min}$ later (i.e., $30 \mathrm{~min}$ after the beginning of CS presentation) were anesthetized to undergo transcardiac perfusion.

Experiment 5 (Expr2). In the immunocytochemical experiments for p-ERK detection in AcbSh by immuno electron microscopy, two lithium-conditioned $\left(\mathrm{CS}^{+}-\mathrm{US}^{+}\right)$and two control groups $\left(\mathrm{CS}^{+}\right.$-US $^{-}$) were given distinct time intervals ( 3 and $23 \mathrm{~min}$, indicated as groups A and B, respectively in results, figures and figures' legends) from the beginning of CS presentation, before anesthesia for transcardiac perfusion.

Experiment 6 (Expr3). Finally, in order to assess the ability of CTA expression to affect NR1, GluR1 and $\mathrm{Thr}^{34}$ - and $\mathrm{Thr}^{75}$ DARPP-32 phosphorylation, two groups of rats $\left(\mathrm{CS}^{+}-\mathrm{US}^{+}\right.$and $\mathrm{CS}^{+}$-US $^{-}$) were presented, $24 \mathrm{~h}$ after CTA acquisition, the sucrose solution $\left(\mathrm{CS}^{+}\right)$for $20 \mathrm{~min}$. An additional control group, never exposed to the acquisition phase $\left(\mathrm{CS}^{-}\right.$-US $^{-}$) was presented tap water for $20 \mathrm{~min}$. Ten minutes after the test for CTA expression (i.e., 30 min after the beginning of $\mathrm{CS}^{+}$or $\mathrm{CS}^{-}$presentation) rats were sacrificed for western blotting analysis for detection of NR1, GluR1, $\mathrm{Thr}^{34}$ - and $\mathrm{Thr}^{75}$-DARPP-32 phosphorylation in PFCx and Acb.

\section{IMMUNOHISTOCHEMISTRY AND IMMUNOCYTOCHEMISTRY}

In CTA acquisition experiments (Acq1 and Acq2), rats were anesthetized with chloral hydrate $(450 \mathrm{mg} / \mathrm{kg}$ i.p.) $30 \mathrm{~min}$ after CS or US presentation. Similarly, in CTA expression experiments, rats were anesthetized $30 \mathrm{~min}$ (Expr1) for immunohistochemistry and 3 and $23 \mathrm{~min}$ (Expr2) for immunocytochemistry, after the beginning of expression test. Under deep anesthesia, rats from Acq1, Acq2 and Expr1 groups were subjected to transcardiac perfusion with ice-cold PBS (Phosphate Buffered Saline: $137 \mathrm{mM}, 2.7 \mathrm{mM} \mathrm{KCl}, 10 \mathrm{mM} \mathrm{Na} \mathrm{HPO}_{4}, 2 \mathrm{mM}$ $\mathrm{KH}_{2} \mathrm{PO}_{4}, \mathrm{pH}$ 7.4) and 4\% paraformaldehyde (PFA). Similarly, under deep anesthesia, rats from Expr2 groups, were subjected to transcardiac perfusion with ice-cold PBS (Phosphate Buffered Saline: $137 \mathrm{mM}, 2.7 \mathrm{mM} \mathrm{KCl}, 10 \mathrm{mM} \mathrm{Na} 2 \mathrm{HPO}_{4}, 2 \mathrm{mM}$ $\mathrm{KH}_{2} \mathrm{PO}_{4}, \mathrm{pH} 7.4$ ), ice cold $4 \%$ paraformaldehyde and $0.5 \%$ glutaraldehyde in $0.1 \mathrm{M}$ cacodylate buffer for immuno electron microscopy processing. After perfusion, brains were removed and post-fixed overnight in the same fixative used for transcardiac perfusion.

\section{Immunoperoxidase processing and quantitative analysis}

Brain sections $(40 \mu \mathrm{m})$ of the regions of interest, PFCx and Acb, were cut, according to the rat brain atlas of Paxinos and Watson (1998) on ice-cold PBS with a vibratome (Leica VT1000, Leica, Germany), kept in ice-cold PBS and processed for immunohistochemistry according to a protocol for free-floating sections. Immunoreactions for p-ERK-positive cells detection was applied to at least three serial slices obtained from each experimental subject. Slice processing and image analysis were performed as described in detail in our previous studies (Acquas et al., 2007; Ibba et al., 2009). Briefly, after incubation with $1 \% \mathrm{H}_{2} \mathrm{O}_{2}$, sections were incubated with $3 \%$ Bovine Serum Albumin (BSA). The incubation with primary antibody [anti di-phosphorylated forms of $E K_{1 / 2}$ phospho-p44/42 MAPK ERK $_{1 / 2}$, Cell Signaling Technology, MA, USA (1:300)] was conducted overnight. On the following day, after rinsing, sections were incubated for $1 \mathrm{~h}$ with the biotinylated secondary antibody (1:800) and after further rinses the sections were incubated in avidin biotin peroxidase complex prepared according to the manufacturer's suggestions (Vectastain ABC kit, Vector Laboratories, CA, USA) and a 3-3'-diaminobenzidine solution $(10 \mathrm{mg} / \mathrm{ml})$ was added until development of brown staining. Sections were mounted onto gelatine-coated slides and processed through alcohol-xylene for light microscopy examination. p-ERK-positive neurons were identified at the lowest magnification (10X) and quantitative analysis was performed using a Zeiss Axioskop 40 light microscope, equipped with PL Floutar 10X $(n a=0.3)$, 40X $(n a=1.00-0.5)$ and $100 \mathrm{X}$ oil $(n a=1.3)$ objectives, coupled with a digital camera (PixeLink, PL-A686C, 6.6 MPixels). Images of the regions 
of interest were obtained at the lowest magnification (10X) according to the rat brain atlas of Paxinos and Watson (1998) and used to automatically count the number of p-ERKpositive neurons/area (density/area) by application of ImageJ in conjunction with automated background subtraction, to avoid experimenter bias, and entropy threshold plug-in (Kapur et al., 1985).

\section{Immuno electron microscopy and quantitative analysis}

Coronal vibratome sections $(100 \mu \mathrm{m})$ were cut on ice-cold PBS with a vibratome (Leica VT1000 P, Leica, Germany). Discs of tissue $(1.2 \mathrm{~mm}$ in diameter) corresponding to a portion of the AcbSh, were high-pressure frozen (Leica EM PACT2) and freeze substituted (Leica EM AFS2) in anhydrous methanol containing $0.5 \%$ uranyl acetate (modified from van Lookeren Campagne et al., 1991). The samples were finally embedded at $-45^{\circ} \mathrm{C}$ in Lowicryl HM20 under UV lights. Thin sections ( $70 \mathrm{~nm}$ thick) obtained on a Leica EM UC6 were collected on Formvar coated nickel grids.

Post-embedding immunolabeling was performed according to Mathiisen et al. (2006): briefly, sections were washed with $0.1 \%$ sodium borohydride and $50 \mathrm{mM}$ glycine in Tris-buffered saline containing $0.1 \%$ Triton X-100 (TBST), blocked in TBST containing $2 \%$ BSA, and then incubated with the primary antibody. We used two rabbit polyclonal antibodies against respectively the un-phosphorylated and the di-phosphorylated forms of $\mathrm{ERK}_{1 / 2}$ (p44/42 MAPK ERK $1 / 2$ and phospho-p44/42 MAPK ERK $1 / 2$ at Thr202/Tyr204, Cell Signaling Technology, MA, USA) diluted 1:50 in the same blocking solution for $2.5 \mathrm{~h}$ at room temperature. The samples were subsequently washed with TBST and incubated with goat anti-rabbit Ig coupled to $10 \mathrm{~nm}$ gold particles diluted 1:100 in the same blocking solution for $1 \mathrm{~h}$. The sections were then washed repeatedly in TBS, post-fixed in $1 \%$ glutaraldehyde in TBS for $5 \mathrm{~min}$, washed with distilled water, and finally stained with uranyl acetate and lead citrate. The grids were observed in a Jeol JEM 1011 electron microscope operating at $100 \mathrm{KV}$ and recorded with an $4 \mathrm{Mp}$ Gatan Orius SC100 ChargeCoupled Device (CCD) camera. To test method specificity in the immunocytochemical procedures the ERK and p-ERK antibodies were omitted and under these conditions no immunoreactivity was observed. Moreover, p-ERK immunostaining signal was abolished when the samples grids were incubated for $1 \mathrm{~h}$ with a mixture of $\mathrm{p}$-ERK and the corresponding blocking peptide for phospho-p44/42 (1:2, Phospho-p44/42 MAPK ERK $_{1 / 2}$ Thr202/Tyr204, Blocking Peptide \#1150, Cell Signaling Technology, MA, USA).

The density of p-ERK nuclear and cytoplasmic labeling (expressed as number of gold particles $/ \mu \mathrm{m}^{2}$ ) was calculated on a total of eleven animals (five controls, and six lithium-conditioned rats from the CTA expression groups (Expr2). More than 30 neuron cell bodies from each animal, belonging to at least two different sections were analyzed and imaged in non-overlapping electron micrographs at a final magnification of 5545. This led to a total of more than 300 neuron cell bodies analyzed, corresponding to nuclear and cytoplasmic areas of, respectively, more than 19,000 and $8000 \mu \mathrm{m}^{2}$. The relative number of $\mathrm{p}$-ERK-positive axo-spinous synaptic contacts, and their density, were counted in the same animals. We randomly sampled a total of 4630 asymmetric synapses, 1046 of which were p-ERK labeled in either pre- or post-synaptic profile. The axo-spinous synaptic contacts were imaged in non-overlapping electron micrographs at a final magnification of 5545. This led to an average of more than 400 asymmetric synapses analyzed in each animal, 96 of which were p-ERK positive. Axo-spinous synaptic contacts were identified for the presence of both synaptic vesicles and post-synaptic density (PSD) respectively in pre- and post-synaptic terminals. To determine the sub-synaptic distribution of p-ERK in dendritic spine profiles the spine head profile was subdivided into three distinct compartments: core, shell, and PSD (Rácz et al., 2004; Boggio et al., 2007). The number of gold particles and their association with each of these compartments were evaluated in a total of more than 200 p-ERK-positive axo-spinous synaptic contacts, from both lithium-conditioned and control rats. Labeling values were expressed as the density of gold particles found in each spine compartment.

\section{Immunoblotting detection of NR1, GluR1, Thr ${ }^{34}$ - and Thr ${ }^{75}$-DARPP-32 phosphorylation and quantitative analysis}

Rats were sacrificed, their heads were briefly immersed (3$5 \mathrm{~s}$ ) in liquid nitrogen, and the brains were rapidly removed and cut into $1 \mathrm{~mm}$ slices using an ice-cold metal brain matrix (ASI Instruments, Inc., MI, USA). The PFCx and Acb were quickly dissected out from the slices corresponding to plates 79 and 10-12, respectively, of the rat brain atlas (Paxinos and Watson, 1998). Tissues were flash-frozen in liquid nitrogen and stored at $-80^{\circ} \mathrm{C}$ until assayed. Immunoblotting was performed as previously described (Scheggi et al., 2007; Danielli et al.,

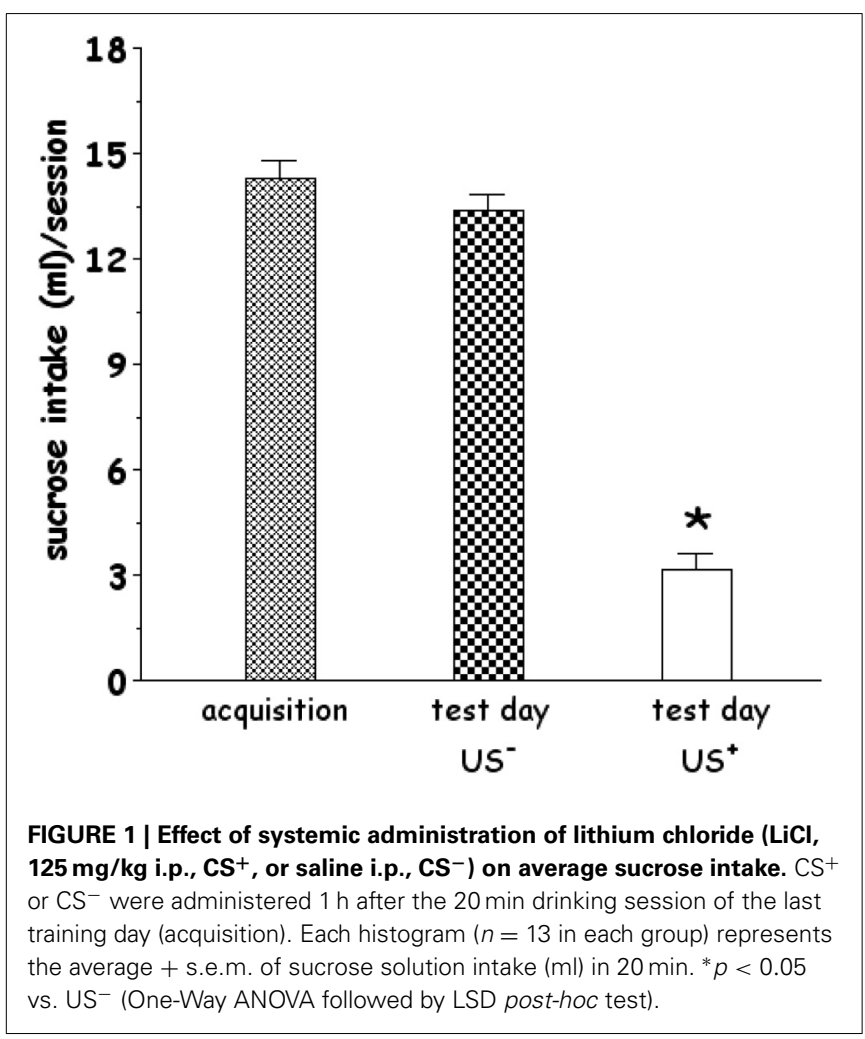




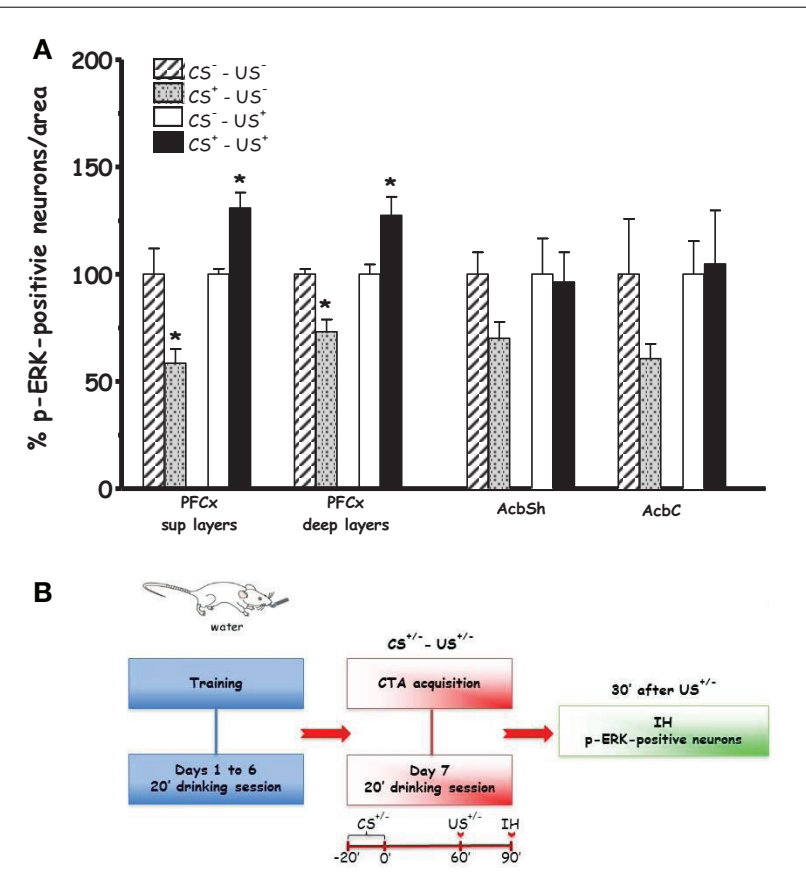

FIGURE 2 | Acquisition (Acq1) (A): Effect of CTA acquisition on \% changes of $p$-ERK-positive neurons/area in the PFCx (superficial and deep layers) and Acb (shell and core). Data, average + s.e.m., are expressed as $\%$ changes with respect to the effect in control groups (CS ${ }^{-}$) set as $100 \%$. *Indicates significant differences $(p<0.05$ ) of \% changes of p-ERK-positive neurons with respect to control groups $\left(\mathrm{CS}^{-}-\mathrm{US}^{-}\right.$and $\left.\mathrm{CS}^{-}-\mathrm{US}^{+}\right)$(One-Way ANOVA followed by LSD post-hoc test) ( $n=4$ in each group); (B): timeline schedule of Acq1 experiment.

2010) and was carried out with phosphorylation-state-specific antibodies against p-Ser897 NR1and p-Ser845 GluR1, (Santa Cruz Biotechnology, CA, USA) and against $\mathrm{p}-\mathrm{Th}^{34}$ DARPP32 and $\mathrm{p}-\mathrm{Thr}^{75}$ DARPP-32 (Cell Signaling Technology, MA, USA), or antibodies not phosphorylation state-specific against total NR1 and GluR1 (Santa Cruz Biotechnology, USA) or total DARPP-32 (Cell Signaling Technology, MA, USA). Membranes were then incubated with peroxidase-conjugated affinity-purified secondary antibodies (Pierce Biotechnology Inc., IL, USA). Antibody binding was detected using a chemiluminescence detection system (Pierce Biotechnology Inc. IL, USA) and quantified with the Versa Doc 1000 Imaging System (BioRad Laboratories, CA, USA). Samples containing the same amount of total proteins from rats in each experimental group were run on the same immunoblots and then analyzed together. In the regions studied, the total amount of DARPP-32 was unmodified in the different experimental groups compared to the control group (data not shown). For each experiment, values obtained from experimental groups were calculated as the percentage of their respective control values.

\section{DRUGS}

Lithium Chloride ( $\mathrm{LiCl}$ ) (Sigma Aldrich, Italy) and Chloral hydrate (Sigma Aldrich, Italy) were dissolved in saline $(\mathrm{NaCl}$

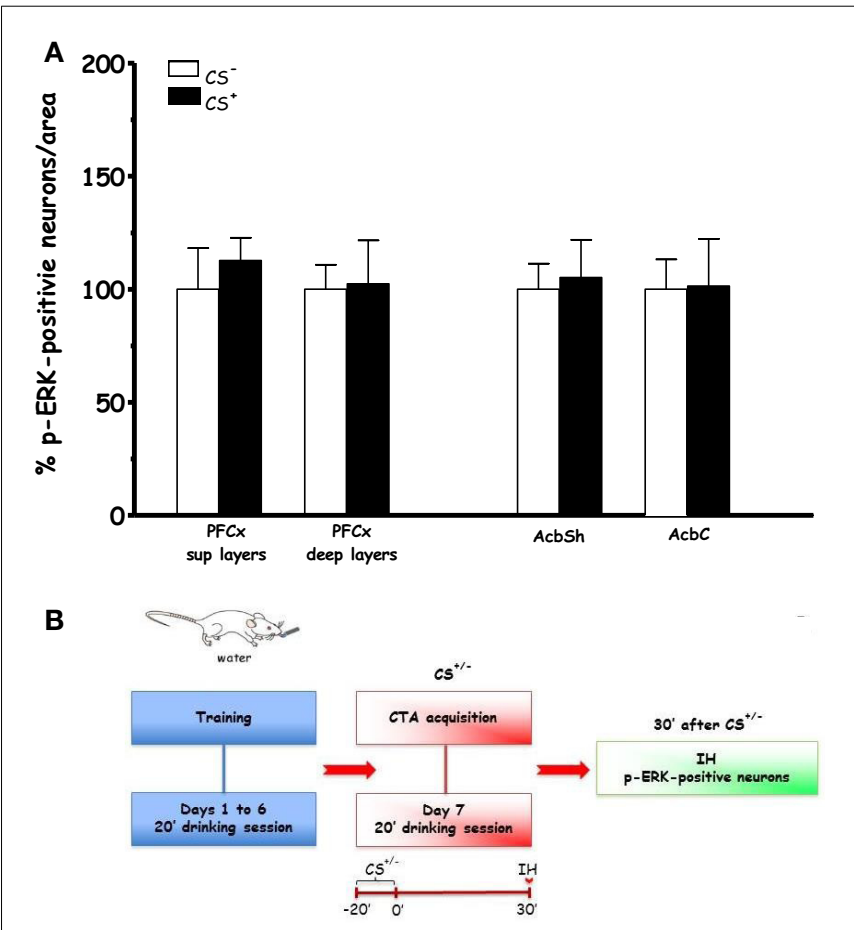

FIGURE 3 | Acquisition (Acq2) (A): Effect of water $\left(\mathrm{CS}^{-}\right)$or sucrose $\left(\mathrm{CS}^{+}\right)$intake on \% changes of p-ERK-positive neurons/area in the PFCx (superficial and deep layers) and Acb (shell and core). Data, average + s.e.m., are expressed as \% changes with respect to the effect in control group ( $\mathrm{CS}^{-}$) set as $100 \%$ ( $n=4$ in each group); (B): timeline schedule of Acq2 experiment.

$0.9 \%$ ) and administered intraperitoneally (i.p.) at the doses, respectively, of $125 \mathrm{mg} / \mathrm{kg} / 2 \mathrm{ml}$ and $450 \mathrm{mg} / \mathrm{kg} / 5 \mathrm{ml}$. D-Sucrose (Sigma Aldrich, Italy) solutions $(15 \% \mathrm{w} / \mathrm{v})$, made in tap water, were freshly prepared on the day of usage.

\section{STATISTICS}

Fluid intake was expressed as average + s.e.m. of sucrose solution $(\mathrm{ml})$ drunk by rats belonging to the same group. Average + s.e.m. of p-ERK-positive neurons/area (\% p-ERK-positive neurons/area) were calculated as \% change with respect to the average number of p-ERK-positive neurons/area of the control groups, set as $100 \%$. These averages were used for statistical comparisons by Analyses of Variance (ANOVAs, Prism 4.0a, GraphPad Software Inc., CA, USA) which were applied to assess the statistical significance of first-order effects of multiple categorical factors. Least significant differences (LSD) post-hoc analyses, whereby allowed by ANOVAs, were applied for multiple comparisons, with the statistical significance set at $p<$ 0.05. Data from electron microscopy experiments were analyzed by One-Way ANOVA with Origin 8 software (OriginLab Co., MA, USA). Statistical analyses of Western blot data were performed with Prism 4.0a, (GraphPad Software Inc., CA, USA); data were analyzed using ANOVA and post-hoc analysis was performed by Bonferroni's test, when $p<0.05$, unless otherwise specified. 


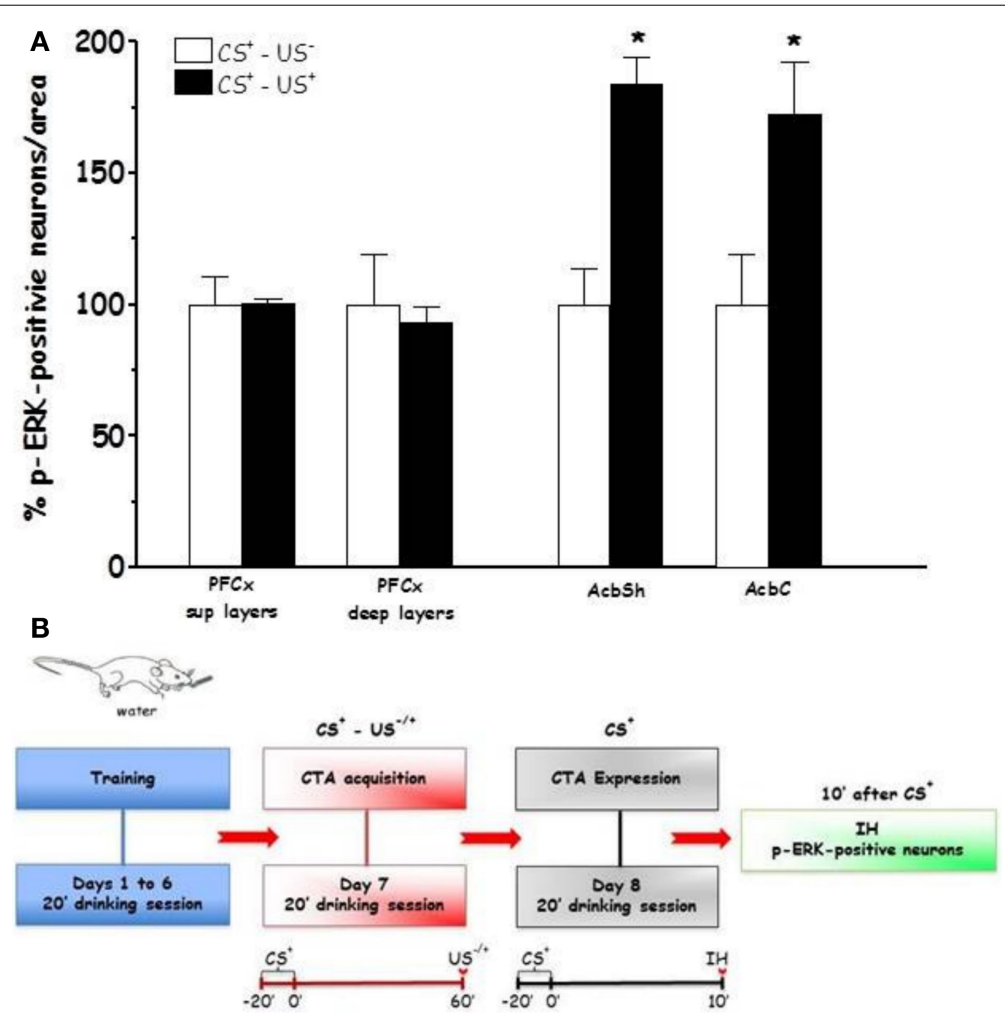

FIGURE 4 | Expression (Expr1) (A): Effect of CTA expression on \% changes of p-ERK-positive neurons/area in the PFCx (superficial and deep layers) and Acb (shell and core). Data, average + s.e.m., are expressed as \% changes with respect to the effect in control group $\left(\mathrm{CS}^{+}-\mathrm{US}^{-}\right)$set as $100 \%$. Lithium chloride ( $\mathrm{LiCl}, 125 \mathrm{mg} / \mathrm{kg}$ i.p., $\mathrm{US}^{+}$) or saline (i.p., US ${ }^{-}$) were administered on the last training day $1 \mathrm{~h}$ after the drinking session. Rats were sacrificed $30 \mathrm{~min}$ after the beginning of the expression test. *Indicates significant differences ( $p<0.05$ ) of \% changes of $p$-ERK-positive neurons with respect to controls ( $\mathrm{CS}^{+}-\mathrm{US}^{-}$) (One-Way ANOVA followed by LSD post-hoc test) ( $n=4$ in each group); (B): timeline schedule of Expr1 experiment.

\section{RESULTS}

\section{EFFECT OF SALINE OR LITHIUM CHLORIDE ADMINISTRATION ON SUCROSE INTAKE (CTA EXPRESSION)}

As shown in Figure 1, rats consumed significantly different volumes of sucrose solution on acquisition and test days [One-Way ANOVA, $\left.F_{(2,36)}=157.95, p<0.001\right]$. Control rats $\left(\mathrm{CS}^{+}\right.$$\left.\mathrm{US}^{-}\right)$drank in the expression test a similar volume $(13.38+$ $0.47 \mathrm{ml} /$ test) compared with average sucrose intake drunk by rats on acquisition day $(14.31+0.51 \mathrm{ml} /$ test $)$. In contrast, rats administered $\mathrm{LiCl}\left(\mathrm{CS}^{+}\right.$-US $\left.{ }^{+}\right)$drank significantly less $(3.15+$ $0.49 \mathrm{ml} /$ test) than controls. LSD post-hoc analysis revealed that $\mathrm{CS}^{+}$-US ${ }^{+}$resulted in a significant reduction of sucrose intake compared to $\mathrm{CS}^{+}-\mathrm{US}^{-}$group.

\section{EFFECT OF CTA ACQUISITION AND EXPRESSION ON ERK PHOSPHORYLATION: IMMUNOHISTOCHEMISTRY EXPERIMENTS}

Figures 2 and 5 show the effect of acquisition of CTA on $\%$ p-ERK-positive neurons in PFCx and Acb (Acq1). OneWay ANOVA revealed a significant effect of $\mathrm{CS}^{+}$in both superficial and deep layers of PFCx ([F(sup)1,8 $=9.14, p<$ $0.02]$ and $\left[F_{(\text {deep }) 1,8}=6.97, p<0.03\right]$, respectively). In addition, One-Way ANOVA provided significant treatment effects (US ${ }^{+}$exposure) in PFCx (superficial $\left[F_{(\text {sup }) 1,6}=16.28, p<\right.$ $0.006]$ and deep $\left[F_{(\text {deep }) 1,6}=7.91, p<0.03\right]$ layers $)$, but not in AcbSh and AcbC $\left(\left[F_{(\text {AcbSh }) 1,6}=0.02, p<0.87\right]\right.$ and
$\left[F_{(\mathrm{AcbC}) 1,6}=0.03, p<0.86\right]$, respectively). LSD post-hoc analysis revealed that $90 \mathrm{~min}$ after $\mathrm{CS}^{+}$exposure p-ERK-positive neurons were significantly decreased with respect to $\mathrm{CS}^{-}$exposure. Moreover, $\mathrm{CS}^{+}$-US ${ }^{+}$association significantly increased \% p-ERK-positive neurons in the superficial and deep layers of the PFCx with respect to $\mathrm{CS}^{-}-\mathrm{US}^{+}$association.

Figure 3 shows the effect on \% p-ERK-positive neurons in PFCx and Acb after scheduled drinking of either sucrose solution $\left(\mathrm{CS}^{+}\right)$or tap water $\left(\mathrm{CS}^{-}\right)$during acquisition (Acq2). Under these conditions, ANOVA revealed that drinking sucrose failed to result in significant main effects in PFCx $\left[F_{(\text {sup }) 1,6}=0.6, p<0.46\right]$ and $\left[F_{(\text {deep }) 1,6}=0.01, p<0.91\right]$ and Acb $\left(\left[F_{(\text {AcbSh }) 1,6}=0.006\right.\right.$, $p<0.80]$ and $\left.\left[F_{(\mathrm{Acb}) 1,6}=0.003, p<0.95\right]\right)$, suggesting that the effect found in the PFCx of rats in Acq1 experiment were attributable to learning the CS-US association.

Figures 4 and 5 show the effect of CTA expression on $\%$ p-ERK-positive neurons in rats $\left(\mathrm{CS}^{+}-\mathrm{US}^{-}\right.$and $\mathrm{CS}^{+}-\mathrm{US}^{+}$ groups) sacrificed $10 \mathrm{~min}$ after completion of CTA test (Expr1). One-Way ANOVA revealed significant effects of conditioning in AcbSh and AcbC $\left(\left[F_{(\text {AcbSh }) 1,6}=8.99, p<0.024\right]\right.$ and $\left[F_{(A c b C) 1,6}=6.84, p<0.039\right]$, respectively). In contrast, OneWay ANOVA failed to reveal significant effects of conditioning on \% changes of p-ERK-positive neurons in PFCx superficial and deep layers $\left(\left[F_{(\sup ) 1,6}=0.0002, p<0.98\right]\right.$ and $\left[F_{(\text {deep }) 1,6}=\right.$ $0.12, p<0.73]$, respectively). LSD post-hoc analysis revealed that 

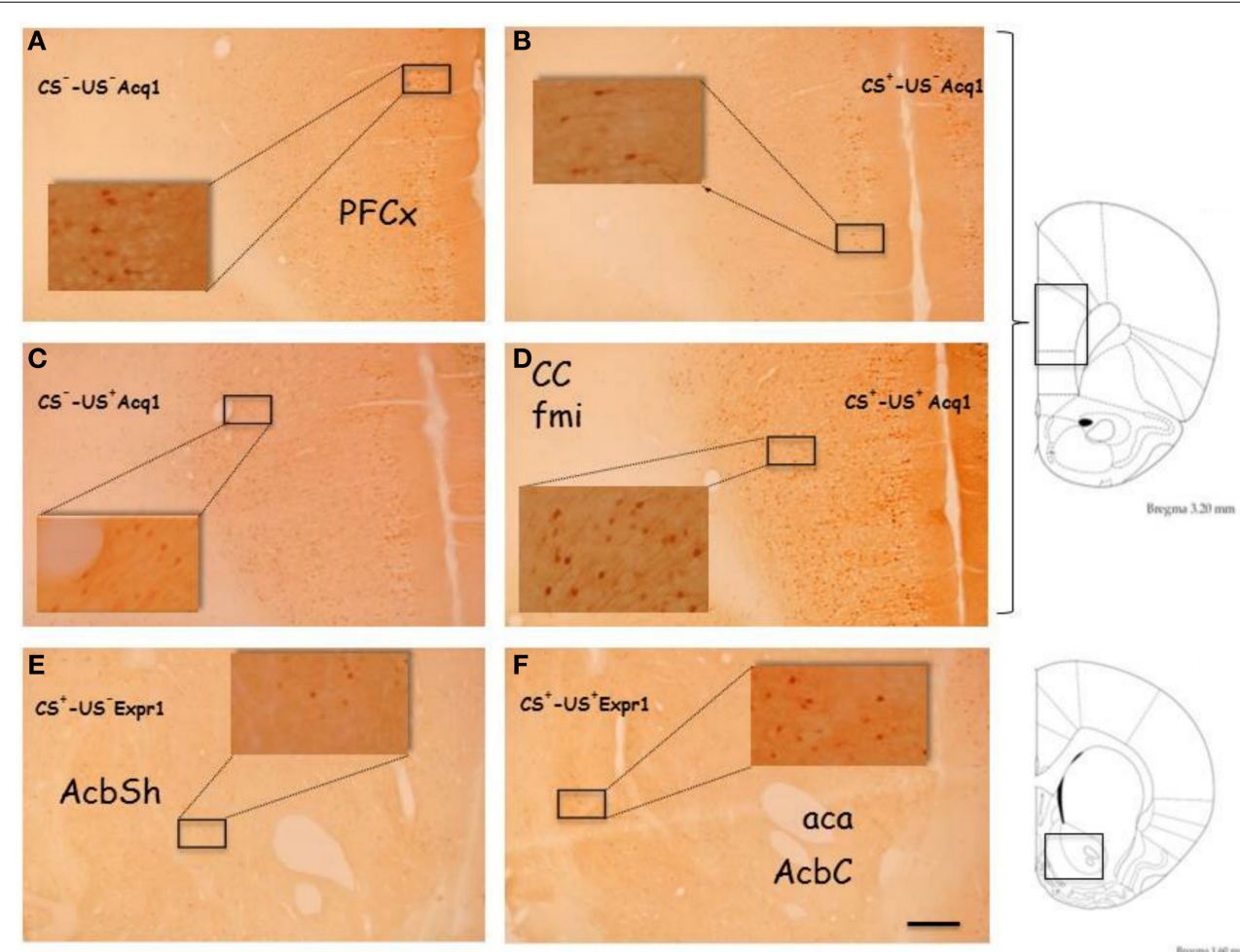

FIGURE 5 | Representative, low (5X) and high (40X, inserts) magnification images of p-ERK immunostaining from PFCx of CS $^{-}-$US $^{-}$(A, Acq1) and CS $^{+}-$US $^{-}$rats (B, Acq1), fom PFCx of $\mathrm{CS}^{-}-\mathrm{US}^{+}$(C, Acq1) and $\mathrm{CS}^{+}-\mathrm{US}^{+}$rats $(D, A c q 1)$ and from Acb of CS $^{+}-$US $^{-}$(E, Expr1) and $\mathbf{C S}^{+}-\mathbf{U S}^{+}$rats (F, Expr1). The images on the right are taken from Paxinos and Watson (1998) rat brain

expression of LiCl-induced CTA increased ERK phosphorylation in AcbSh and AcbC.

\section{EFFECT OF CTA EXPRESSION ON SUBCELLULAR ERK PHOSPHORYLATION DISTRIBUTION IN AcbSh: IMMUNO ELECTRON MICROSCOPY EXPERIMENTS}

Neuron cell bodies p-ERK signal was mainly expressed in the nucleus, and to a lesser extent in the cytoplasm (Figures 6A and $\mathbf{C}$ ); on the contrary the signal of un-phosphorylated ERK was expressed exclusively inside the cytoplasm (Figure 6B). Nuclear p-ERK signal was often present in clusters of 2-4 gold particles, frequently close to the nuclear membrane (Figure 6C).

The average density of p-ERK nuclear labeling in AcbSh neurons of lithium-conditioned $\left(\mathrm{CS}^{+}-\mathrm{US}^{+}\right)$rats did not differ between animals sacrificed 3 or $23 \mathrm{~min}$ from beginning of testing (expression groups $\mathrm{A}$ and $\mathrm{B}$ ) and thus data were pooled. Average density of p-ERK nuclear labeling in AcbSh neurons of lithium-conditioned $\left(\mathrm{CS}^{+}-\mathrm{US}^{+}\right)$ rats was significantly higher than in control rats $\left(\mathrm{CS}^{+}-\mathrm{US}^{-}\right)$ $\left(0.93 \pm 0.05\right.$ vs. $0.58 \pm 0.03$ gold particles $/ \mu \mathrm{m}^{2} ;$ Figure $7 \mathrm{~A}$ and Table 1, One-Way ANOVA, $p<0.01)$. Cytoplasmic pERK signal was significantly lower than nuclear density (One-Way ANOVA, $p<0.01$ ) and not significantly different between lithium-conditioned and control rats (Figure $7 \mathbf{A}$ and Table 1). atlas and indicate the antero-posterior gradient $(\mathrm{mm})$ used to cut the brains and to select the slices for immunostaining. Abbreviations: aca, anterior commissure, anterior part; AcbSh, Accumbens Shell; AcbC, Accumbens Core; CC fmi, forceps minor of the corpus callosum; PFCx, Prefrontal cortex. Scale bar indicates $200 \mu \mathrm{m}$ in low magnification images.

p-ERK immunoreactivity in the AcbSh medium spiny neurons, during CTA expression, was not restricted to the cell body, but extended to dendritic and axonal processes (Figures 6D-F). Accordingly, p-ERK labeling was detected in dendritic spines, mainly at synaptic plasma membrane domains, but also in presynaptic axonal boutons forming connections with dendritic spines (Figures 6D-F). The number of p-ERK labeled axospinous contacts was higher in the AcbSh of lithium treated rats $\left(\mathrm{CS}^{+}\right.$-US $\left.{ }^{+}\right)$with respect to controls $\left(\mathrm{CS}^{+}\right.$-US $\left.^{-}\right)(31.6 \pm 4.4 \mathrm{vs}$. $25.5 \pm 3.7$ out of the total number of p-ERK-labeled excitatory profiles; expression groups $\mathrm{A}+\mathrm{B}$; One-Way ANOVA, $p=0.01$ ) (Figure 7B and Table 1).

We also investigated the distribution of p-ERK immunoreactivity within AcbSh dendritic spines in both lithium-conditioned $\left(\mathrm{CS}^{+}{ }_{-} \mathrm{US}^{+}\right)$and control $\left(\mathrm{CS}^{+}{ }_{-} \mathrm{US}^{-}\right)$rats from $\mathrm{A}+\mathrm{B}$ expression groups. In both groups a large majority of p-ERK immunoreactivity was expressed inside PSD whereas only a minority of gold nanoparticles was associated with shell and core of spines' head (Figures 7C and D).

EFFECT OF CTA ACQUISITION AND EXPRESSION ON NR1, GIUR1, Thr ${ }^{34}$-, AND Thr ${ }^{75}$-DARPP-32 PHOSPHORYLATION LEVELS: IMMUNOBLOTTING EXPERIMENTS

For the immunoblotting experiments rats of CTA acquisition experiment 3 (Acq3) were sacrificed $3 \mathrm{~h}$ after the last treatment 


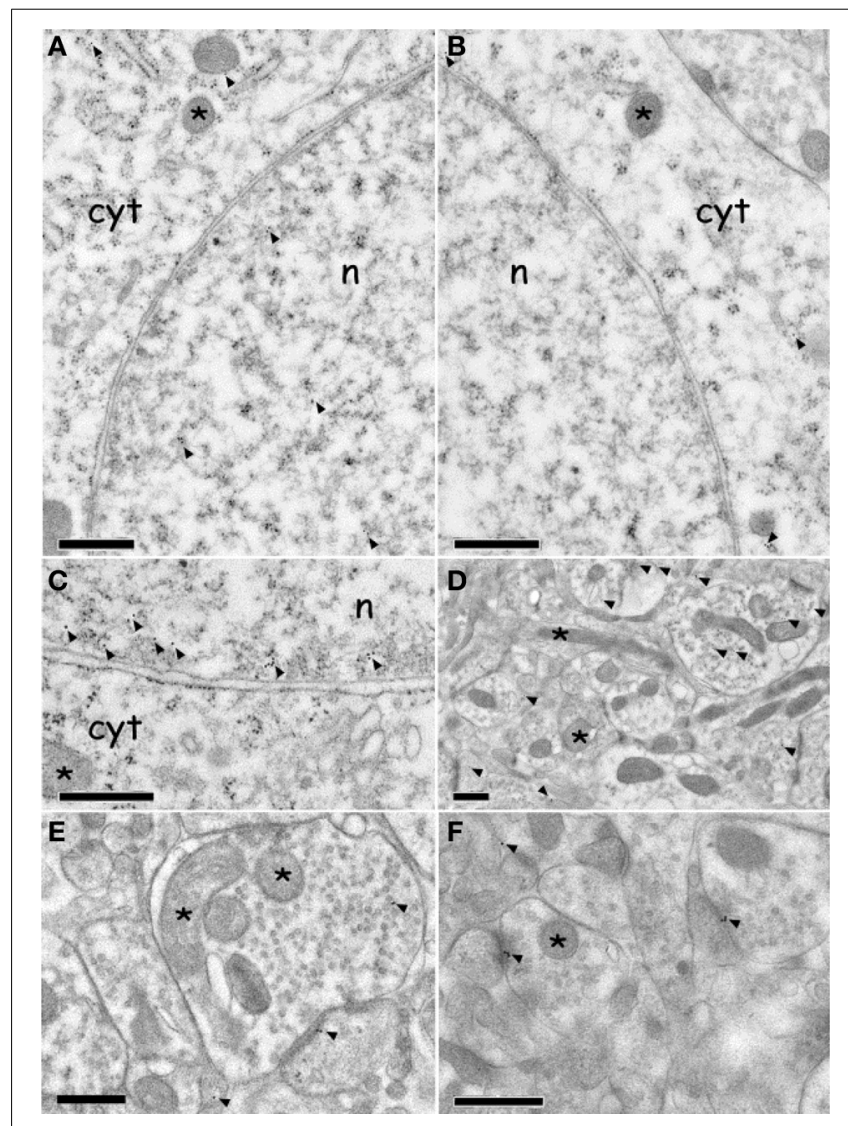

FIGURE 6 | Immuno electron microscopy localization of ERK and p-ERK inside the AcbSh neurons of $\left(\mathbf{C S}^{+}-\mathrm{US}^{+}\right.$) rats (Expr2). (A,C): $p$-ERK immunolabeling in neuron cell body nucleus and cytoplasm (arrowheads). The asterisks indicate mitochondria. (B): ERK immunolabeling in neuron cell body cytoplasm (arrowheads). The asterisks indicate mitochondria. (D-F): p-ERK immunolabeling in dendrites, dendritic spines, and pre-synaptic boutons (arrowheads). Asterisks indicate mitochondria. Abbreviations: cyt, cytoplasm; n, nucleus. Scale bars are $0.5 \mu \mathrm{m}$.
(US) in order to avoid a possible confounding factor in CTA acquisition response, due to the modifications induced by sucrose (CS) consumption on NR1, GluR1, Thr ${ }^{34}$ - and $\mathrm{Thr}^{75}$-DARPP-32, phosphorylation patterns (Danielli et al., 2010). The phosphorylation levels of NR1, GluR1, $\mathrm{Thr}^{34}$ and $\mathrm{Thr}^{75}$ DARPP-32 were assessed in PFCx, AcbSh, and AcbC and the results are shown in Table 2. Statistical analysis of phosphorylation levels of the NR1 and GluR1 subunits of NMDA and AMPA glutamate receptors indicated a difference between groups in the levels of $\mathrm{p}-\mathrm{NR} 1$ in PFCx $\left[F_{(3,19)}=8.19 ; p<0.01\right]$. Data analysis by One-Way ANOVA indicated no significant difference among $\mathrm{p}-\mathrm{Thr}^{34}$ and $\mathrm{p}$-Thr ${ }^{75}$ DARPP-32 levels in all 3 regions of the four experimental groups (Table 2). Bonferroni's multiple comparison test revealed that $\mathrm{p}-\mathrm{NR} 1$ levels were higher in the group of rats that acquired CTA than in other groups $(p<0.01)$ (Table 2$)$. No statistically significant differences were found in the levels of p-NR1 in AcbSh and AcbC. Moreover, no statistical differences were found in the levels of p-GluR1 in PFCx nor Acb. In the CTA expression experiment 6 (Expr3), rats were sacrificed 10 min after

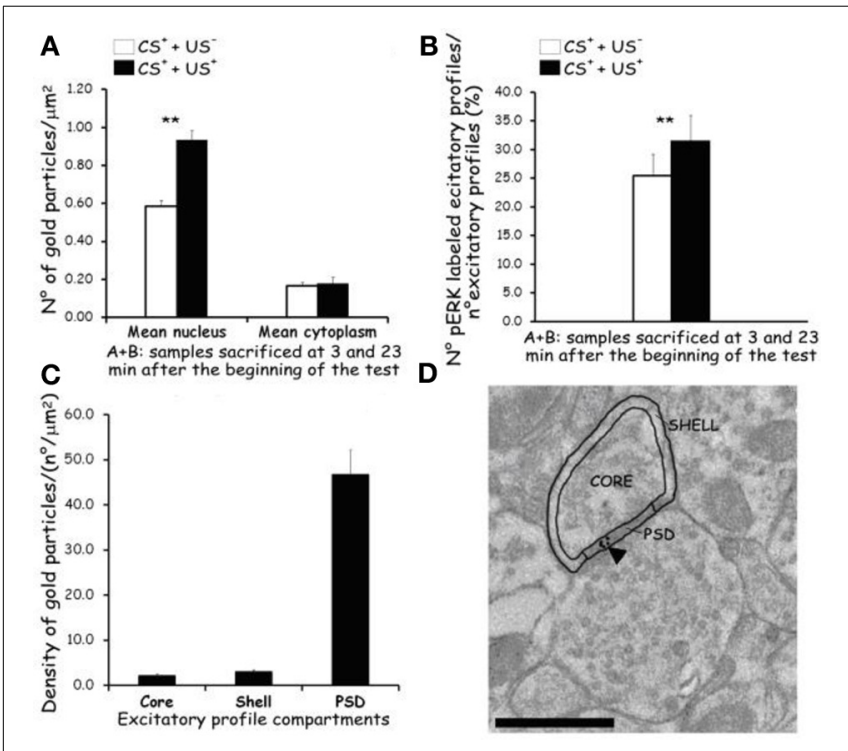

FIGURE 7 | Effects of CTA expression on subcellular p-ERK distribution. (A): histograms showing p-ERK density inside nucleus and cytoplasm of neuron cell bodies belonging to AcbSh of lithium conditioned $\left(\mathrm{CS}^{+}-\mathrm{US}^{+}\right.$) and control rats $\left(\mathrm{CS}^{+}-\mathrm{US}^{-}\right)$(Expr2); histograms represent pooled data obtained from rats sacrificed 3 (group A) and 23 (group B) min after the beginning of testing. Values are average + s.e.m. ${ }^{* *}$ Indicate significant differences $\left(p<0.01\right.$ ) in average density gold particles between US' ${ }^{-}$and $\mathrm{US}^{+}$rats (One-Way ANOVA). (B): histograms showing the percentage of p-ERK-positive synaptic profiles out of the total number of synapses that were randomly sampled inside the AcbSh of lithium conditioned $\left(\mathrm{CS}^{+}-\mathrm{US}^{+}\right.$) and control rats $\left(\mathrm{CS}^{+}-\mathrm{US}^{-}\right)$(Expr2); histograms represent pooled data obtained from rats sacrificed 3 (group A) and 23 (group B) min after the beginning of testing. Values are average + s.e.m. ${ }^{* *}$ Indicate significant differences $(p<0.01)$ in number of pERK labeled excitatory profiles $(\%)$ between US $^{-}$and US ${ }^{+}$rats (One-Way ANOVA). (C,D): sub-synaptic distribution of p-ERK in dendritic spine compartments (core, shell, and PSD). (C): histograms showing the density of gold particles (number of gold particles/ $\mu \mathrm{m}^{2}$ ) observed in each sub-synaptic compartment. (D):

Representative TEM micrograph of a dendritic spine subdivided in three compartments: core, shell, and PSD. Arrowhead points to gold particles. Scale bar is $500 \mathrm{~nm}$.

being presented the sucrose solution (CS) for $20 \mathrm{~min}$ (i.e., $30 \mathrm{~min}$ after the beginning of CS presentation). The phosphorylation pattern of NR1 and GluR1 subunits and $\mathrm{Thr}^{34}$ and $\mathrm{Thr}^{75}$ DARPP-32, was measured after testing for CTA expression (Table 3). OneWay ANOVA of the results indicated no significant differences among the levels of phosphoproteins in PFCx, AcbSh, and AcbC of these experimental groups.

\section{DISCUSSION}

The results of the present study demonstrate that acquisition and expression of lithium-induced CTA results in differential phosphorylation of ERK and NR1 subunit of NMDA glutamate receptor in rats' $\mathrm{PFCx}$ and Acb. In particular, acquisition of lithium-induced CTA resulted in increased phosphorylation of ERK and NR1 in the PFCx while, expression of lithium-induced CTA disclosed an increase of ERK phosphorylation in AcbSh and AcbC. Furthermore, immuno electron microscopy analysis of the compartmentalization of p-ERK signal within the AcbSh of rats from CTA expression group revealed 
Table 1 | Phospho-ERK average density and percent of p-ERK-labeled excitatory profiles inside the AcbSh of lithium treated $\left(\mathrm{CS}^{+}-\mathrm{US}^{+}\right)$and control rats $\left(\mathrm{CS}^{+}-\mathrm{US}^{-}\right)$obtained pooling the results from rats sacrificed at 3 and $23 \mathrm{~min}$ after the beginning of test.

\begin{tabular}{|c|c|c|c|}
\hline \multicolumn{2}{|c|}{$\mathbf{C S}^{+}-\mathrm{US}^{-}$} & \multicolumn{2}{|c|}{$\mathrm{CS}^{+}-\mathrm{US}^{+}$} \\
\hline \multicolumn{2}{|c|}{$\begin{array}{l}A+B: \text { samples sacrificed at } 3 \text { and } \\
23 \text { min after start of expression test }\end{array}$} & \multicolumn{2}{|c|}{$\begin{array}{l}A+B \text { : samples sacrificed at } 3 \text { and } \\
23 \text { min after start of expression test }\end{array}$} \\
\hline \multicolumn{2}{|c|}{ p-ERK average density } & \multicolumn{2}{|c|}{ p-ERK average density } \\
\hline Nuclear & Cytoplasmic & Nuclear & Cytoplasmic \\
\hline $\begin{array}{c}\text { Mean } \pm \text { s.e.m. } \\
0.58 \pm 0.03\end{array}$ & $\begin{array}{c}\text { Mean } \pm \text { s.e.m. } \\
0.17 \pm 0.02\end{array}$ & $\begin{aligned} \text { Mean } & \pm \text { s.e.m. } \\
0.93 & \pm 0.05^{* *}\end{aligned}$ & $\begin{array}{c}\text { Mean } \pm \text { s.e.m. } \\
0.18 \pm 0.04\end{array}$ \\
\hline
\end{tabular}

$\%$ p-ERK-labeled excitatory profiles \% p-ERK-labeled excitatory profiles

$$
25.5 \pm 3.7
$$$$
31.6 \pm 4.4^{* *}
$$

pERK positive synaptic profiles values are expressed as percentage of $p$ ERK-labeled excitatory profiles out of the total number of excitatory profiles; ${ }^{*}$ Indicate respectively significant differences $(p<0.01)$ of average density gold particles and number of pERK labeled excitatory profiles (\%) between US and $\mathrm{US}^{+}$rats (One-Way ANOVA)

a significant increase of nuclear p-ERK immunostaining as well as a significantly higher number of p-ERK labeled axospinous contacts, mostly co-localized with PSD, with respect to control rats.

The study was also aimed to assess whether or not acquisition and expression of lithium-induced CTA would result in changes of phosphorylation levels of GluR1 AMPA glutamate receptor subunit and DARPP-32 in the same brain regions. The results revealed that, at least at the time intervals and experimental conditions used, both acquisition and expression of CTA were not accompanied by modifications in the phosphorylation of these substrates.

In agreement with previous studies from our (Fenu et al., 2001; Fenu and Di Chiara, 2003) and other laboratories (Yasoshima et al., 2006), we found that a single CS-US association reliably induced CTA (Figure 1). Thus, the observed effects of CTA acquisition and expression on ERK and NR1 phosphorylation can be considered behaviorally relevant, i.e., phase- and brain region-dependent. The immunohistochemical analysis revealed that the number of p-ERK-positive neurons/area was significantly reduced in the PFCx (both in the superficial and deep layers) $90 \mathrm{~min}$ after $\mathrm{CS}^{+}$exposure (i.e., $30 \mathrm{~min}$ after $\mathrm{US}^{-}$) This decrease in PFCx p-ERK-positive neurons may be part of the delayed response to a prolonged, $20 \mathrm{~min}$, exposure to a palatable taste, while at an earlier time the number of p-ERK-positive neurons/area was not modified (Figure 3). This modification may be an expression of the complex phenomenon of neuronal plasticity in response to a relevant natural stimulus (a caloric palatable food) in an area, the PFCx, anatomically (Berendse and Groenewegen, 1990; Brog et al., 1993; Heidbreder and Groenewegen, 2003) and functionally (Cardinal et al., 2002) connected with the AcbSh, where short-term habituation to palatable taste is observed in dopaminergic transmission (Bassareo et al., 2002; Rauggi et al., 2005; Danielli et al., 2010). Notably, in both superficial and deep layers of PFCx $\mathrm{CS}^{+}-\mathrm{US}^{+}$association increased, $30 \mathrm{~min}$ after US administration, the number of p-ERK-positive neurons/area (Figure 2). This effect could not be attributed to US or CS on their own. In particular, failure of US to elicit pERK expression in the PFCx is in agreement with previous studies showing that systemic lithium administration fails to affect ERK phosphorylation in mouse PFCx (Longoni et al., 2011); furthermore, the present results also indicate that sucrose consumption fails to affect ERK phosphorylation in PFCx (Figure 3) when measured $30 \mathrm{~min}$ after $\mathrm{CS}^{+}$exposure, overall suggesting that increased ERK phosphorylation in PFCx accompanies the learning of the CS-US association. This conclusion appears in agreement with the observation that CTA acquisition was also accompanied by increased phosphorylation of NR1 receptor subunit in the same area. However, the modifications of ERK and NR1 receptor subunit phosphorylation observed in PFCx are temporarily distinct since assays for p-ERK, on one hand, and assays for p-NR1, p-GluR1, and p-DARPP-32, on the other hand, were conducted in slices obtained from rats sacrificed $30 \mathrm{~min}$ and $3 \mathrm{~h}$, respectively, after US administration. As previously pointed out, such longer time interval for western blotting assay was selected in order to avoid possible confounding effects due to modifications in the phosphorylation levels of NR1, GluR1, and DARPP-32 in the PFCx of rats receiving sucrose solution as CS (Rauggi et al., 2005; Danielli et al., 2010). In fact, exposure to a palatable taste has been previously shown to result in increased NR1, GluR1, and Thr ${ }^{34}$-DARPP-32 phosphorylation in PFCx and Acb (Rauggi et al., 2005; Danielli et al., 2010). Hence, after a shorter time interval from CS, as in Experiment 1 (Acq1), we wouldn't have been able to dissociate between CS and US-CS association-elicited increases. Notably, sucrose consumption produces a DAergic response associated with transient modifications in NR1, GluR1 and DARPP-32 phosphorylation, in the PFCx, and Acb, that are dependent on the activation of a DA $D_{1}$ receptor-PKA signaling pathway (Rauggi et al., 2005; Danielli et al., 2010). These modifications have been proposed to play a role in the formation of a gustatory memory trace (Danielli et al., 2010) and may represent the mechanism underpinning the increase in p-ERK positive neurons found in the PFCx $90 \mathrm{~min}$ after sucrose exposure and $30 \mathrm{~min}$ after US. Indeed, p-ERK levels are increased by activation of the $\mathrm{DA} \mathrm{D}_{1}$ receptor-PKA signaling pathway or by NMDA transmission with different mechanisms, such as increased MEK activity or inhibition of STEP, a tyrosine phosphatase that inactivates ERK (Valjent et al., 2005; Nagai et al., 2007). The long-lasting increase in p-NR1 levels still present in the PFCx several hours after acquisition of CTA could represent a marker of sustained NMDA receptor activity. However, while our experimental design could not contribute to disclose any possible mechanistic and temporal relationship between ERK and NR1 receptor subunit phosphorylation (Xia et al., 1996; Hardingham et al., 2001), these results point to the PFCx as an anatomical site where neuronal plasticity takes place during and shortly after CTA acquisition (Gilmartin and Helmstetter, 2010). This possibility appears in agreement with the observation that timedependent ERK phosphorylation in PFCx also plays a critical role in the extinction of acquired CTA (Lin et al., 2010). On the other hand, phosphorylation of AMPA receptor GluR1 subunit and 
Table 2 | Levels of p-NR1, p-GluR1 p-Thr ${ }^{34}$ and $\mathrm{p}-\mathrm{Thr}^{75}$ DARPP-32, in different brain regions after CTA acquisition.

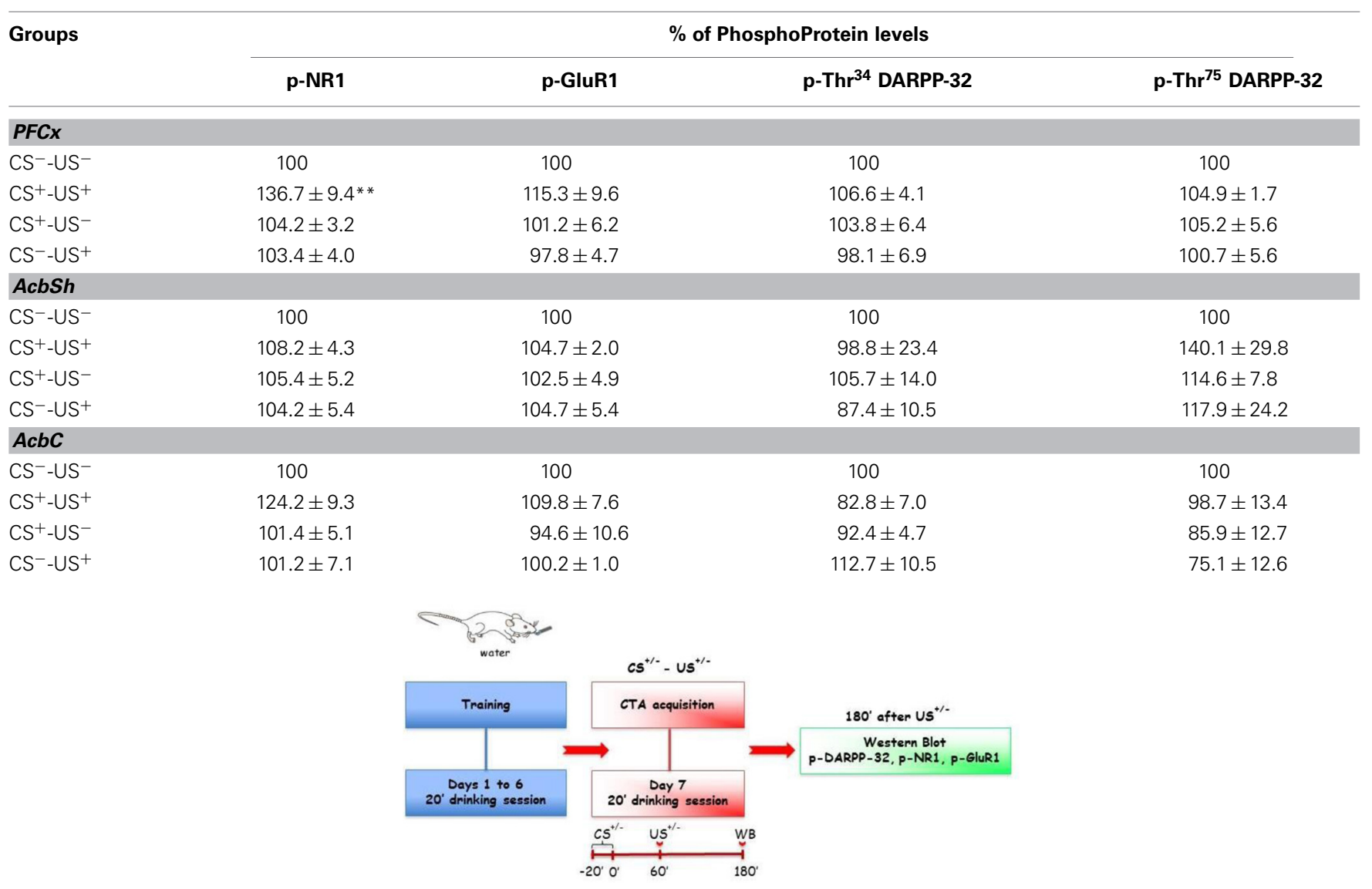

Values are the average \pm s.e.m. percentage of values in saline treated $\left(\mathrm{CS}^{-}\right)$rats. Figure depicts timeline schedule of $\boldsymbol{A c q} 3$ experiment. ${ }^{* *}$ Indicates $p<0.01$ with respect to $\mathrm{CS}^{-}-\mathrm{US}^{-}$.

DARPP-32 (either at $\mathrm{Thr}^{34}$ - and $\mathrm{Thr}^{75}$-) was unmodified, suggesting that long-lasting modifications in PFCx phosphorylation levels of these substrates are not involved in CTA acquisition or expression.

In agreement with previous studies reporting that the Acb plays a critical role in associative learning and, in particular in lithium-induced CTA (Fenu et al., 2001; Fenu and Di Chiara, 2003; Yasoshima et al., 2006; Ramírez-Lugo et al., 2007), we found that expression of lithium-induced CTA resulted in ERK activation in both the AcbSh and AcbC. Previous studies aimed at addressing the role of AcbSh and AcbC DA in CTA acquisition disclosed a critical role for $\mathrm{DA}_{1}$ receptors in the AcbSh (Fenu et al., 2001). Notably, although a close relationship exists between activation of DA $D_{1}$ receptors signaling and ERK phosphorylation (Girault et al., 2007), in this study we detected changes of ERK phosphorylation in both the AcbSh and AcbC only during CTA expression. This finding appears in agreement with two lines of evidence obtained upon memory retrieval of conditioned taste aversion: (i) the observation of increased c-FOS-like immunoreactivity in both AcbSh and AcbC (Yasoshima et al., 2006) and (ii) the observation of a greater signal intensity of manganeseenhanced functional magnetic resonance imaging (MEMRI) in AcbSh and AcbC of conditioned rats (Inui-Yamamoto et al.,
2010). However, no modifications were observed in the CTA acquisition phase in these Acb sub-regions and, as previously mentioned, also no changes in the pattern of NR1, GluR1 nor DARPP-32 phosphorylation were detected in the AcbSh or AcbC. Thus, while there is no doubt that DA plays a critical role in associative learning (Hoffman and Beninger, 1988; Mark et al., 1991; Fenu et al., 2001; Di Chiara, 2002), the present results overall suggests the possibility that on one hand stimulation of AcbSh DA $D_{1}$ receptors during CTA acquisition (Fenu et al., 2001) does not result in changes of ERK phosphorylation and, on the other hand, that increased ERK phosphorylation upon CTA expression may not necessarily involve $\mathrm{DA}_{1} \mathrm{D}_{1}$ receptors. This interpretation appears consistent with the lack of evidence, to the best of our knowledge, in support of a role of DA $D_{1}$ receptors in CTA expression and also with the observation that intraoral saccharin administration to rats undergone lithium-induced CTA was responsible of a significant decrease of DA transmission in medial Acb (Mark et al., 1991).

The present study also represents the first immunocytochemical analysis of ERK and p-ERK expression inside AcbSh neurons of rats undergone testing to assess CTA expression. We coupled post-embedding immunolabeling with high pressure freezing (HPF) of pre-fixed rat brain tissues and freeze substitution 
Table 3 | Levels of p-NR1, p-GluR1, p-Thr ${ }^{34}$ and $\mathrm{p}-\mathrm{Thr}^{75}$ DARPP-32, in different brain regions after CTA expression.

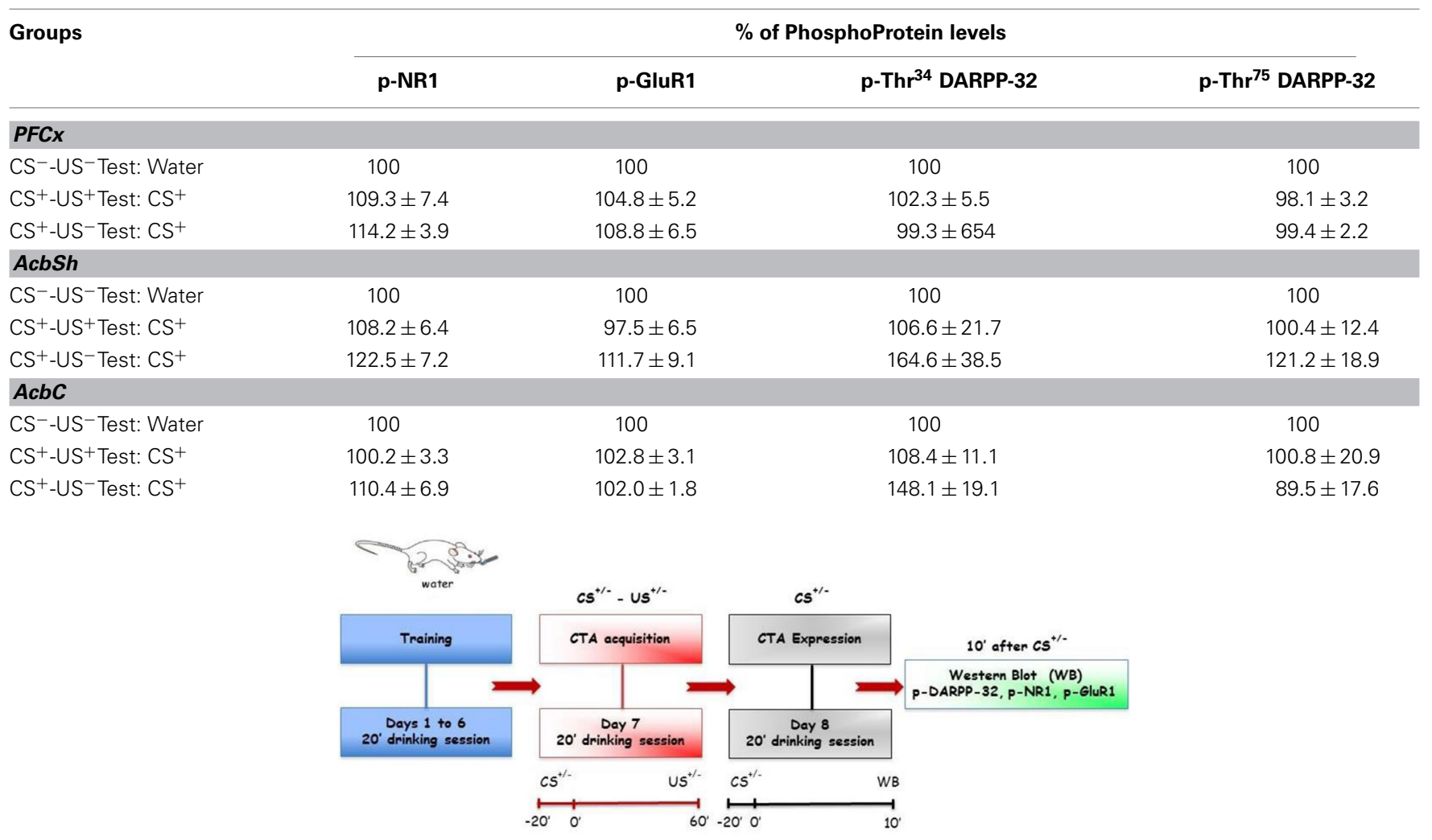

Values are the average \pm s.e.m. percentage of values in saline treated $\left(C S^{-}\right)$rats. Figure depicts timeline schedule of Expr3 experiment.

(FS) (Sosinsky et al., 2008). This procedure yielded better brain ultrastructure and preserved tissue antigenicity better than after conventional EM processing (Sosinsky et al., 2008), being therefore suitable for post-embedding immunogold labeling (Humbel and Schwartz, 1989; van Genderen et al., 1991; van Lookeren Campagne et al., 1991) and quantitative immunocytochemistry (Oprins et al., 1994). Under these conditions, the observed ERK and p-ERK subcellular localization was largely coherent with previous immunocytochemical analyses performed on other brain regions (Liu et al., 2005; Zhu et al., 2006; Boggio et al., 2007; Xiao et al., 2011). In accordance with these studies, we found p-ERK expression inside the nuclei of AcbSh medium size spiny neurons and, to a lesser extent, in perinuclear cytoplasm and dendritic processes, mainly at pre- and post-synaptic profiles. In addition, in accordance with the results of the immunohistochemical analysis showing an increase of p-ERK positive neurons following CTA expression, we observed a significant increase of nuclear $\mathrm{p}$-ERK immunostaining in AcbSh neurons of lithium-conditioned rats. These results suggest that AcbSh neurons of lithium-conditioned rats may be transcriptionally activated during CTA expression, given the role that $\mathrm{p}$-ERK plays in phosphorylating several transcription factors once translocated inside the nucleus (Sétáló et al., 2001). Also, the number of p-ERK labeled axo-spinous contacts in the AcbSh of lithium-conditioned rats was significantly higher than in controls suggesting that CTA expression may have evoked an ERK activation at asymmetric contacts. Thus, in the
AcbSh p-ERK may play a role in synaptic activation during CTA expression, as it has been shown in rat visual cortex after visual stimulation (Boggio et al., 2007). Moreover, we observed that in AcbSh of both conditioned and control rats p-ERK was localized preferentially in correspondence of PSD. This result, although different from the findings reported by Boggio et al. (2007) in rat visual cortex, appears consistent with the identification of p-ERK immunoreactivity at some of the post-synaptic active zones in pre-Bötzinger complex interneurons (Liu et al., 2005) and might suggest a close correlation between synaptic transmission and intracellular signaling transduction. Intriguingly, a specific role for synaptic function has been suggested for $\mathrm{ERK}_{2}$ isoform that has been detected in the PSD95 fraction obtained from rat synaptosomes and synaptic plasma membrane (Suzuki et al., 1995, 1999).

The immunohistochemical results in the AcbSh suggest that similar complex subcellular and synaptic changes might also take place in the AcbC. However, in light of the distinct afferents to the Acb activated upon CTA retrieval (Inui et al., 2013) and in light of the anatomical and functional differences between AcbSh and AcbC, future experiments are warranted to provide further insights on the subcellular distribution of p-ERK signal as well as on its role and significance in this Acb sub-region upon CTA expression.

In conclusion, this study reveals differential increases of PFCx ERK and NR1 phosphorylation, during CTA acquisition, and 
AcbSh and AcbC ERK phosphorylation during CTA expression. In particular increased ERK phosphorylation in the AcbSh during CTA expression, involves mechanisms both at synaptic level and in the regulation of gene expression (nuclear activation) as already shown in other brain areas (Boggio et al., 2007; Sindreu et al., 2007). Finally, in light of the increase of dendritic spines density found in AcbSh and AcbC during CTA expression (Acquas et al., 2011), these data overall suggest that local activation of pERK at synaptic sites may represent a mechanism associated with synaptic plasticity.

\section{ACKNOWLEDGMENTS}

Authors are grateful to Marta Orlando for support during TEM analysis and gratefully acknowledge the financial support of Fondazione Compagnia di San Paolo (Turin, Italy), Bando Neuroscience 2008, to M. Graziella De Montis, Andrea Falqui, and Elio Acquas and of Istituto Italiano di Tecnologia (IIT, Genoa, Italy) to Andrea Falqui.

\section{SUPPLEMENTARY MATERIALS}

The Supplementary Material for this article can be found online at: http://www.frontiersin.org/journal/10.3389/fnbeh.2014. 00153/abstract

\section{REFERENCES}

Acquas, E., Carboni, E., Leone, P., and Di Chiara, G. (1989). SCH 23390 blocks drug-conditioned place-preference and place-aversion: anhedonia (lack of reward) or apathy (lack of motivation) after dopamine-receptor blockade? Psychopharmacology 99, 151-155. doi: 10.1007/BF00442800

Acquas, E., and Di Chiara, G. (1994). D1 receptor blockade stereospecifically impairs the acquisition of drug-conditioned place preference and place aversion. Behav. Pharmacol. 5, 555-569. doi: 10.1097/00008877-199410000-00001

Acquas, E., Pisanu, A., Spiga, S., Plumitallo, A., Zernig, G., and Di Chiara, G. (2007). Differential effects of intravenous R,S-(+/-)-3,4methylenedioxymethamphetamine (MDMA, Ecstasy) and its $\mathrm{S}(+)$ - and $\mathrm{R}(-)$-enantiomers on dopamine transmission and extracellular signal regulated kinase phosphorylation (pERK) in the rat nucleus accumbens shell and core. J. Neurochem. 102, 121-132. doi: 10.1111/j.1471-4159.2007.04451.x

Acquas, E., Vinci, S., Fenu, S., De Montis, M. G., Gambarana, C., Scheggi, S., et al. (2011). Conditioned taste aversion elicited ERK activation and changes of dendritic spines density: an immunohistochemical, Golgi-Cox and electron microscopy study. Behav. Pharmacol. 22(Suppl. S), E38-E38.

Akirav, I. (2007). NMDA Partial agonist reverses blocking of extinction of aversive memory by GABA(A) agonist in the amygdala. Neuropsychopharmacology 32, 542-550. doi: 10.1038/sj.npp.1301050

Barki-Harrington, L., Elkobi, A., Tzabary, T., and Rosenblum, K. (2009). Tyrosine phosphorylation of the $2 \mathrm{~B}$ subunit of the NMDA receptor is necessary for taste memory formation. J. Neurosci. 29, 9219-9226. doi: 10.1523/JNEUROSCI.5667-08.2009

Bassareo, V., De Luca, M. A., and Di Chiara, G. (2002). Differential expression of motivational stimulus properties by dopamine in nucleus accumbens shell versus core and prefrontal cortex. J. Neurosci. 22, 4709-4719.

Berendse, H. W., and Groenewegen, H. J. (1990). Organization of the thalamostriatal projections in the rat, with special emphasis on the ventral striatum. J. Comp. Neurol. 299, 187-228. doi: 10.1002/cne.902990206

Berman, D. E., Hazvi, S., Rosenblum, K., Seger, R., and Dudai, Y. (1998). Specific and differential activation of mitogen-activated protein kinase cascades by unfamiliar taste in the insular cortex of the behaving rat. J. Neurosci. 18, 10037-10044.

Bernstein, I. L., and Koh, M. T. (2007). Molecular signaling during taste aversion learning. Chem. Senses 32, 99-103. doi: 10.1093/chemse/bjj032

Boggio, E. M., Putignano, E., Sassoè-Pognetto, M., Pizzorusso, T., and Giustetto, M. (2007). Visual stimulation activates ERK in synaptic and somatic compartments of rat cortical neurons with parallel kinetics. PLOS ONE 2:e604. doi: 10.1371/journal.pone.0000604
Brog, J. S., Salyapongse, A., Deutch, A. Y., and Zahm, D. S. (1993). The patterns of afferent innervation of the core and shell in the "accumbens" part of the rat ventral striatum: immunohistochemical detection of retrogradely transported fluorogold. J. Comp. Neurol. 338, 255-278. doi: 10.1002/cne.903380209

Cannon, C. M., Scannell, C. A., and Palmiter, R. D. (2005). Mice lacking dopamine D1 receptors express normal lithium chloride-induced conditioned taste aversion for salt but not sucrose. Eur. J. Neurosci. 21, 2600-2604. doi: 10.1111/j.14609568.2005.04077.x

Cardinal, R. N., Parkinson, J. A., Hall, J., and Everitt, B. J. (2002). Emotion and motivation: the role of the amygdala, ventral striatum, and prefrontal cortex. Neurosci. Biobehav. Rev. 26, 321-352. doi: 10.1016/S0149-7634(02) 00007-6

Cui, Z., Lindl, K. A., Mei, B., Zhang, S., and Tsien, J. Z. (2005). Requirement of NMDA receptor reactivation for consolidation and storage of nondeclarative taste memory revealed by inducible NR1 knockout. Eur. J. Neurosci. 22, 755-763. doi: 10.1111/j.1460-9568.2005.04257.x

Danielli, B., Scheggi, S., Grappi, S., Marchese, G., De Montis, M. G., Tagliamonte, A., et al. (2010). Modifications in DARPP-32 phosphorylation pattern after repeated palatable food consumption undergo rapid habituation in the nucleus accumbens shell of non-food-deprived rats. J. Neurochem. 112, 531-541. doi: 10.1111/j.1471-4159.2009.06483.x

Di Chiara, G. (2002). Nucleus accumbens shell and core dopamine: differential role in behavior and addiction. Behav. Brain Res. 137, 75-114. doi: 10.1016/S01664328(02)00286-3

Dunn, L. T., and Everitt, B. J. (1988). Double dissociations of the effects of amygdala and insular cortex lesions on conditioned taste aversion, passive avoidance, and neophobia in the rat using the excitotoxin ibotenic acid. Behav. Neurosci. 102, 3-23. doi: 10.1037/0735-7044.102.1.3

Elkobi, A., Ehrlich, I., Belelovsky, K., Barki-Harrington, L., and Rosenblum, K. (2008). ERK-dependent PSD-95 induction in the gustatory cortex is necessary for taste learning, but not retrieval. Nat. Neurosci. 11, 1149-1151. doi: $10.1038 / \mathrm{nn} .2190$

Fasano, S., and Brambilla, R. (2011). Ras-ERK signaling in behavior: old questions and new perspectives. Front. Behav. Neurosci. 5:79. doi: 10.3389/fnbeh.2011.00079

Fenu, S., Bassareo, V., and Di Chiara, G. (2001). A role for dopamine D1 receptors of the nucleus accumbens shell in conditioned taste aversion learning. J. Neurosci. 21, 6897-6904.

Fenu, S., Cadoni, C., and Di Chiara, G. (2010). Conditioned saccharin avoidance and sensitization to drugs of abuse. Behav. Brain Res. 214, 248-253. doi: 10.1016/j.bbr.2010.05.044

Fenu, S., and Di Chiara, G. (2003). Facilitation of conditioned taste aversion learning by systemic amphetamine: role of nucleus accumbens shell dopamine D1 receptors. Eur. J. Neurosci. 18, 2025-2030. doi: 10.1046/j.14609568.2003.02899.x

Fenu, S., Rivas, E., and Di Chiara, G. (2005). Differential role of dopamine in drugand lithium conditioned saccharin avoidance. Physiol. Behav. 85, 37-43. doi: 10.1016/j.physbeh.2005.04.002

Fenu, S., Rivas, E., and Di Chiara, G. (2009). Differential involvement of dopamine D1 receptors in morphine- and lithium-conditioned saccharin avoidance. Physiol. Behav. 96, 73-77. doi: 10.1016/j.physbeh.2008.08.017

Ferreira, G., Ferry, B., Meurisse, M., and Lévy, F. (2006). Forebrain structures specifically activated by conditioned taste aversion. Behav. Neurosci. 120, 952-962. doi: 10.1037/0735-7044.120.4.952

Garcia, J., Kimeldorf, D. J., and Koelling, R. A. (1955). Conditioned aversion to saccharin resulting from exposure to gamma radiation. Science 122, 157-158.

Gilmartin, M. R., and Helmstetter, F. J. (2010). Trace and contextual fear conditioning require neural activity and NMDA receptor-dependent transmission in the medial prefrontal cortex. Learn. Mem. 17, 289-296. doi: 10.1101/lm.15 97410

Girault, J. A., Valjent, E., Caboche, J., and Hervé, D. (2007). ERK2: a logical AND gate critical for drug-induced plasticity? Curr. Opin. Pharmacol. 7, 77-85. doi: 10.1016/j.coph.2006.08.012

Greenshaw, A. J., and Buresová, O. (1982). Learned taste aversion to saccharin following intraventricular or intraperitoneal administration of d,l-amphetamine. Pharmacol. Biochem. Behav. 17, 1129-1133. doi: 10.1016/0091-3057(82) 90107-1

Groenewegen, H. J., Berendse, H. W., Wolters, J. G., and Lohman, A. H. M. (1990). "The anatomical relationship of the prefrontal cortex with the striatopallidal system, the thalamus and the amygdala: evidence for a parallel organization," in 
Progress in Brain Research, Vol. 85, eds H. B. M. Uylings, C. G. VanEden, J. P. C. DeBruin, M. A. Corner, and M. G. P. Feenstra (Amsterdam: Elsevier Science Publishers), 95-118.

Guzmán-Ramos, K., Osorio-Gómez, D., Moreno-Castilla, P., and BermúdezRattoni, F. (2010). Off-line concomitant release of dopamine and glutamate involvement in taste memory consolidation. J. Neurochem. 114, 226-236. doi: 10.1111/j.1471-4159.2010.06758.x

Hardingham, G. E., Arnold, F. J., and Bading, H. (2001). A calcium microdomain near NMDA receptors: on switch for ERK-dependent synapse-to-nucleus communication. Nat. Neurosci. 4, 565-566. doi: 10.1038/88380

Heidbreder, C. A., and Groenewegen, H. J. (2003). The medial prefrontal cortex in the rat: evidence for a dorso-ventral distinction based upon functional and anatomical characteristics. Neurosci. Biobehav. Rev. 27, 555-579. doi: 10.1016/j.neubiorev.2003.09.003

Hoffman, D. C., and Beninger, R. J. (1988). Selective D1 and D2 dopamine agonists produce opposing effects in place conditioning but not in conditioned taste aversion learning. Pharmacol. Biochem. Behav. 31, 1-8. doi: 10.1016/00913057(88)90302-4

Humbel, B. M., and Schwartz, H. (1989). "Freeze-substitution for immunochemistry," in Immunogold Labelling in Cell Biology, eds A. J.Verkleij and J. L. M. Leunissen (Boca Raton, FL: CRC Press), 115-134.

Ibba, F., Vinci, S., Spiga, S., Peana, A. T., Assaretti, A. R., Spina, L., et al. (2009). Ethanol-induced extracellular signal regulated kinase: role of dopamine D1 receptors. Alcohol Clin. Exp. Res. 33, 858-867. doi: 10.1111/j.15300277.2009.00907.x

Inui, T., Inui-Yamamoto, C., Yoshioka, Y., Ohzawa, I., and Shimura, T. (2013). Activation of efferents from the basolateral amygdala during the retrieval of conditioned taste aversion. Neurobiol. Learn. Mem. 106, 210-220. doi: 10.1016/j.nlm.2013.09.003

Inui-Yamamoto, C., Yoshioka, Y., Inui, T., Sasaki, K. S., Ooi, Y., Ueda, K., et al. (2010). The brain mapping of the retrieval of conditioned taste aversion memory using manganese-enhanced magnetic resonance imaging in rats. Neuroscience 167, 199-204. doi: 10.1016/j.neuroscience.2010.02.027

Kapur, J. N., Sahoo, P. K., and Wong, K. C. (1985). A new method for gray-level picture thresholding using the entropy of the histogram. Comput. Vis. Graph. Image Process. 29, 273-285. doi: 10.1016/0734-189X(85)90125-2

Kwon, B., and Houpt, T. A. (2012). Mitogen-activated protein kinase in the amygdala plays a critical role in lithium chloride-induced taste aversion learning. Neurobiol. Learn. Mem. 97, 132-139. doi: 10.1016/j.nlm.2011. 10.005

Languille, S., Davis, S., Richer, P., Alcacer, C., Laroche, S., and Hars, B. (2009). Extracellular signal-regulated kinase activation is required for consolidation and reconsolidation of memory at an early stage of ontogenesis. Eur. J. Neurosci. 30, 1923-1930. doi: 10.1111/j.1460-9568.2009.06971.x

Lin, P. Y., Wang, S. P., Tai, M. Y., and Tsai, Y. F. (2010). Differential involvement of medial prefrontal cortex and basolateral amygdala extracellular signal-regulated kinase in extinction of conditioned taste aversion is dependent on different intervals of extinction following conditioning. Neuroscience 171, 125-133. doi: 10.1016/j.neuroscience.2010.08.066

Liu, J. P., Liu, Y. Y., Wong-Riley, M. T. T., Liu, H. J., and Ju, G. (2005). A group of neurokinin-1 receptor-immunoreactive neurons expressing phosphoextracellular signal-regulated protein kinases in the pre-Bötzinger complex of rats. J. Neurosci. Res. 80, 260-267. doi: 10.1002/jnr.20445

Longoni, R., Spina, L., Vinci, S., and Acquas, E. (2011). The MEK inhibitor SL327 blocks acquisition but not expression of lithium-induced conditioned place aversion: a behavioral and immunohistochemical study. Psychopharmacology 216, 63-73. doi: 10.1007/s00213-011-2192-9

Mark, G. P., Blander, D. S., and Hoebel, B. G. (1991). A conditioned stimulus decreases Extracellular dopamine in the nucleus accumbens after the development of a learned taste aversion. Brain Res. 551, 308-310. doi: 10.1016/00068993(91)90946-S

Mathiisen, T. M., Nagelhus, E. A., Jouleh, B., Torp, R., Frydenlund, D. S., Mylonakou, M. N., et al. (2006). "Postembedding immunogold cytochemistry of membrane molecules and amino acid transmitters in the central nervous system," in Neuroanatomical Tract-Tracing 3: Molecules, Neurons, and Systems, eds L. Zaborszky, F. G. Wouterlood, and J. L. Lanciego (New York, NY: Springer), 72-108. doi: 10.1007/0-387-28942-9_3

McGaugh, J. L. (2000). Memory-a century of consolidation. Science 287, 248-251. doi: $10.1126 /$ science.287.5451.248
Mickley, G. A., Kenmuir, C. L., Yocom, A. M., Wellman, J. A., and Biada, J. M. (2005). A role for prefrontal cortex in the extinction of a conditioned taste aversion. Brain Res. 1051, 176-182. doi: 10.1016/j.brainres.2005. 05.033

Nagai, T., Takuma, K., Kamei, H., Ito, Y., Nakamichi, N., Ibi, D., et al. (2007). Dopamine D1 receptors regulate protein synthesis-dependent long-term recognition memory via extracellular signal-regulated kinase $1 / 2$ in the prefrontal cortex. Learn Mem. 14, 117-125. doi: 10.1101/lm.461407

Núñez-Jaramillo, L., Rangel-Hernández, J. A., Burgueño-Zúñiga, B., and Miranda, M. I. (2012). Activation of nucleus accumbens NMDA receptors differentially affects appetitive or aversive taste learning and memory. Front. Behav. Neurosci. 6:13. doi: 10.3389/fnbeh.2012.00013

Oprins, A., Geuze, H. J., and Slot, J. W. (1994). Cryosubstitution dehydration of aldehyde-fixed tissue: a favorable approach to quantitative immunocytochemistry. J. Histochem. Cytochem. 42, 497-503. doi: 10.1177/42.4.8126376

Paxinos, G., and Watson, C. (1998). The Rat Brain in Stereotaxic Coordinates, 4th Edn. San Diego, CA: Academic Press.

Rácz, B., Blanpied, T. A., Ehlers, D. E., and Weinberg, R. J. (2004). Lateral organization of endocytic machinery in dendritic spines. Nat. Neurosci. 7, 917-918. doi: $10.1038 / \mathrm{nn} 1303$

Ramírez-Lugo, L., Núñez-Jaramillo, L., and Bermúdez-Rattoni, F. (2007). Taste memory formation: role of nucleus accumbens. Chem. Senses 32, 93-97. doi: 10.1093/chemse/bj1023

Rauggi, R., Scheggi, S., Cassanelli, A., De Montis, M. G., Tagliamonte, A., and Gambarana, C. (2005). The mesolimbic dopaminergic response to novel palatable food consumption increases dopamine-D1 receptor-mediated signalling with complex modifications of the DARPP-32 phosphorylation pattern. J. Neurochem. 92, 867-877. doi: 10.1111/j.1471-4159.2004. 02920.x

Rosenblum, K., Berman, D. E., Hazvi, S., Lamprecht, R., and Dudai, Y. (1997). NMDA receptor and the tyrosine phosphorylation of its $2 \mathrm{~B}$ subunit in taste learning in the rat insular cortex. J. Neurosci. 17, 5129-5135.

Runyan, J. D., and Dash, P. K. (2004). Intra-medial prefrontal administration of SCH-23390 attenuates ERK phosphorylation and long-term memory for trace fear conditioning in rats. Neurobiol. Learn. Mem. 82, 65-70. doi: 10.1016/j.nlm.2004.04.006

Scheggi, S., Raone, A., De Montis, M. G., Tagliamonte, A., and Gambarana, C. (2007). Behavioral expression of cocaine sensitization in rats is accompanied by a distinct pattern of modifications in the PKA/DARPP-32 signaling pathway. J. Neurochem. 103, 1168-1183. doi: 10.1111/j.1471-4159.2007. 04818.x

Scott, T. R. (2011). Learning through the taste system. Front. Syst. Neurosci. 5:87. doi: $10.3389 /$ fnsys.2011.00087

Sétáló, G., Singh, M., Guan, X., and Toran-Allerand, C. D. (2001). Cellular localization of estradiol-induced phospho-ERK1/2 in mouse cerebral cortical explants: the roles of heat shock protein 90 and MEK2. J. Neurobiol. 50, 1-12. doi: 10.1002/neu. 10000

Shiflett, M. W., and Balleine, B. W. (2011). Molecular substrates of action control in cortico-striatal circuits. Prog. Neurobiol. 95, 1-13. doi: 10.1016/j.pneurobio.2011.05.007

Simonyi, A., Serfozo, P., Parker, K. E., Ramsey, A. K., and Schachtman, T. R. (2009). Metabotropic glutamate receptor 5 in conditioned taste aversion learning. Neurobiol. Learn. Mem. 92, 460-463. doi: 10.1016/j.nlm.2009.05.002

Sindreu, C. B., Scheiner, Z. S., and Storm, D. R. (2007). Ca(2+)-Stimulated adenylyl cyclases regulate ERK-dependent activation of MSK1 during fear conditioning. Neuron 53, 79-89. doi: 10.1016/j.neuron.2006.11.024

Sosinsky, G. E., Crum, J., Ying, Z. J., Lanman, J., Smarr, B., Terada, M., et al. (2008). The combination of chemical fixation with high pressure freezing and freeze substitution preserves highly labile tissue ultrastructure for electron tomography applications. J. Struct. Biol. 161, 359-371. doi: 10.1016/j.jsb.2007. 09.002

Suzuki, T., Mitake, S., and Murata, S. (1999). Presence of up-stream and downstream -Brain Res. 840, 36-44. doi: 10.1016/S0006-8993(99)01762-X

Suzuki, T., Okumura-Noji, K., and Nishida, E. (1995). ERK2-type mitogen activated protein kinase (MAPK) and its substrates in postsynaptic density fractions from the rat brain. Neurosci. Res. 22, 277-285. doi: 10.1016/01680102(95)00902-6

Valjent, E., Pascoli, V., Svenningsson, P., Paul, S., Enslen, H., Corvol, J. C., et al. (2005). Regulation of a protein phosphatase cascade allows convergent 
dopamine and glutamate signals to activate ERK in the striatum. Proc. Natl. Acad. Sci. U.S.A. 102, 491-496. doi: 10.1073/pnas.0408305102

van Genderen, I. L., van Meer, G., Slot, J. W., Geuze, H. J., and Voorhout, W. F. (1991). Subcellular localization of Forssman glycolipid in epithelial MDCK cells by immuno-electronmicroscopy after freeze-substitution. J. Cell Biol. 115, 1009-1019. doi: 10.1083/jcb.115.4.1009

van Lookeren Campagne, M., Oestreicher, A. B., van der Krift, T. P., Gispen, W. H., and Verkleij, A. J. (1991). Freeze-substitution and Lowicryl HM20 embedding of fixed rat brain: suitability for immunogold ultrastructural localization of neural antigens. J. Histochem. Cytochem. 39, 1267-1279. doi: 10.1177/39.9.18 33448

Xia, Z., Dudek, H., Miranti, C. K., and Greenberg, M. E. (1996). Calcium influx via the NMDA receptor induces immediate early gene transcription by a MAP kinase/ERK-dependent mechanism. J. Neurosci. 16, 5425-5436.

Xiao, B., Han, F., Wang, H. T., and Shi, Y. X. (2011). Single-prolonged stress induces increased phosphorylation of extracellular signal-regulated kinase in a rat model of post-traumatic stress disorder. Mol. Med. Rep. 4, 445-449. doi: 10.3892/mmr.2011.459

Yamamoto, T., Fujimoto, Y., Shimura, T., and Sakai, N. (1995). Conditioned taste aversion in rats with excitotoxic brain lesions. Neurosci. Res. 22, 31-49. doi: 10.1016/0168-0102(95)00875-T

Yasoshima, Y., Morimoto, T., and Yamamoto, T. (2000). Different disruptive effects on the acquisition and expression of conditioned taste aversion by blockades of amygdalar ionotropic and metabotropic glutamatergic receptor subtypes in rats. Brain Res. 869, 15-24. doi: 10.1016/S0006-8993(00) 02397-0
Yasoshima, Y., Scott, T. R., and Yamamoto, T. (2006). Memory-dependent c-Fos expression in the nucleus accumbens and extended amygdala following the expression of a conditioned taste aversive in the rat. Neuroscience 141, 35-45. doi: 10.1016/j.neuroscience.2006.03.019

Zhu, J. H., Fengli, G., Shelburne, J., Watkins, S., and Chu, C. T. (2006). Localization of phosphorylated ERK/MAP kinases to mitochondria and autophagosomes in lewy body diseases. Brain Pathol. 13, 473-481. doi: 10.1111/j.17503639.2003.tb00478.x

Conflict of Interest Statement: The authors declare that the research was conducted in the absence of any commercial or financial relationships that could be construed as a potential conflict of interest.

Received: 23 December 2013; accepted: 14 April 2014; published online: 07 May 2014 Citation: Marotta R, Fenu S, Scheggi S, Vinci S, Rosas M, Falqui A, Gambarana $C$, De Montis MG and Acquas E (2014) Acquisition and expression of conditioned taste aversion differentially affects extracellular signal regulated kinase and glutamate receptor phosphorylation in rat prefrontal cortex and nucleus accumbens. Front. Behav. Neurosci. 8:153. doi: 10.3389/fnbeh.2014.00153

This article was submitted to the journal Frontiers in Behavioral Neuroscience.

Copyright (c) 2014 Marotta, Fenu, Scheggi, Vinci, Rosas, Falqui, Gambarana, De Montis and Acquas. This is an open-access article distributed under the terms of the Creative Commons Attribution License (CC BY). The use, distribution or reproduction in other forums is permitted, provided the original author(s) or licensor are credited and that the original publication in this journal is cited, in accordance with accepted academic practice. No use, distribution or reproduction is permitted which does not comply with these terms. 